\title{
Grillparzers Lustspiel Weh dem, der lügt! und die Iphigenie-Dramen Goethes und des Euripides
}

\author{
Hansgerd Delbrück
}

Eva Hoffmann, Tübingen, zugeeignet ${ }^{1}$

Die Verwandtschaft des Lustspiel-Titels Weh dem, der lügt! mit Iphigenies Ausrufen: "Zwischen uns sei Wahrheit!" und "O weh der Lüge!" ist offensichtlich und wurde in der Forschung wiederholt notiert. ${ }^{2}$ Grillparzers Stück ist jedoch nicht einfach die Transposition eines klassischen Schauspiels der Humanität in ein klassisches Lustspiel der Humanität. Weh dem, der lügt! konnte nicht von Goethe, sondern nur von Grillparzer geschrieben werden. Die beiden Autoren waren in verschiedenen Kultur- und Theatertraditionen aufgewachsen, und ihre Temperamente waren im ganzen eher verschieden als verwandt. Obendrein war Grillparzer zweiundvierzig Jahre jünger als Goethe, dessen Iphigenie in eine frühe Schaffensperiode zurückreicht, während Weh dem, der lügt! erst nach Goethes Tod beendet wurde.

Grillparzer selbst sah sein Verhältnis zu Goethe gekennzeichnet durch Affinität und Distanz. Bei aller Bewunderung für Goethe litt er, und zwar schon lange vor einer persönlichen Begegnung und vor seiner Arbeit an Weh dem, der lügt!, unter dem Zwiespältigen ihrer Beziehung. In einem Tagebucheintrag vom 20. Juni 1810 notiert er, daß er über Werthers Leiden zu Goethe gefunden und dann begierig von Goethe alles gelesen habe, dessen er habhaft werden konnte: Faust, Tasso, Iphigenie, Clavigo, Die Geschwister, Egmont; er war überwältigt, "betete Goethe an." Der nächste Satz aber lautet: "Und doch schreibt sich von dieser Zeit auch der Anfang meines Trübsinns, meiner Melancholie her, so

1 Mit herzlichem Dank für wichtige Hinweise zu Goethes Iphigenie-Dichtung.

2 So etwa bei W. E. Yates (Grillparzer. A critical introduction. Cambridge 1972, S. 211), der sich durch Weh dem, der lügt! insgesamt an das Humanitätsideal in Schillers Aufsatz Über das Pathetische und in Herders Briefen zur Beförderung der Humanität erinnert fühlt, während ihn der Titel des Lustspiels an Goethes Schauspiel der Humanität, Iphigenie, gemahnt. Mit dem Hinweis auf Iphigenies "O weh der Lüge" $(I V, 1)$ nennt er die Standards von Gregor im wesentlichen denen der Goetheschen Heldin verwandt: ihrem Ideal reiner Menschlichkeit, gegründet auf Wahrhaftigkeit und Vertrauen. Alle diese Hinweise sind einleuchtend, doch eignet sich im folgenden zum dramaturgischen Vergleich natürlich nur Iphigenie. 
daß nach der gewöhnlichen Art der Menschen zu schließen, ich den Grund in diesen Ereignissen zu finden glaubte." Er machte also ausgerechnet seine GoetheLektüre für das Ausbrechen seiner depressiven Stimmungen verantwortlich, die er nach dem Sprachgebrauch des 18. und 19. Jahrhunderts mit dem Namen Melancholie belegte, und war sich doch in seinem späteren Bericht über jene Zeit sehr wohl bewußt, daß er da in Goethe nur einen oberflächlich zureichenden Grund für seine Probleme mit sich selbst gefunden hatte. Plötzlich, so hören wir, habe er die eigene Hand zu schwach gefühlt für die von Goethe erreichte "Zartheit des Miniaturmalers", die er sich zum Muster nehmen wollte: "Meine Ruhmsucht war in ihrem Innersten angegriffen." (IV, 255-256) Er sei damals, kurz gesagt, zum ersten Mal in den Zustand gefallen, in dem er sich zur Zeit befinde.

Fünf Tage später schreibt er wieder aus demselben Zustand heraus, und er beschreibt ihn auf eine Weise, die bereits an die erste Szene seines erst fast drei Jahrzehnte später vollendeten Lustspiels Weh dem, der lügt! erinnert. Die Tagebuchnotiz vom 25. Juni 1810 lautet: "[...] dieses immerwährende Zweifeln an meinem eigenen Werte, dieses Sehnen meines Herzens nach Nahrung ohne je befriedigt zu werden; ich kann es nicht mehr aushalten. Drum fort, fort aus dieser Lage! Hinaus in die Welt, um diesen Trübsinn, wenn auch nicht zu stillen, aber doch wenigstens zu übertäuben." (IV, 257) Im Lustspiel jammert der Küchenjunge Leon, er quäle sich so, daß er wahrlich nicht mehr könne. Der Grund: er habe durch die Schuld des Bischofs seine "gute Meinung" von sich als Koch verloren, er fühle sich als Versager. Und seine Folgerung: "Kurz, ich geh fort, ich halts nicht länger aus." (V, 75ff.)

Im Jahre 1810 redete Grillparzer sich selbst eine solche Flucht wieder aus. Das Genie habe es halt schwer überall auf der Welt. Sechzehn Jahre später dagegen, im Herbst 1826, als er dann doch versuchte, seinem Trübsinn durch Reisen zu entkommen, ${ }^{3}$ suchte er sich als Reiseziel Deutschland aus, und zwar um Goethes willen, "den zu sprechen oder auch nur zu sehen [ihn] im voraus glücklich machte." Obwohl er Goethe keineswegs unkritisch gegenüberstand, war es ihm damals, "als ob schon sein Anblick hinreichend wäre, [ihm] neuen Mut in die Seele zu gießen."

Die Zitate stammen aus seiner Selbstbiographie von 1853, in der auch seine Erinnerungen an die Begegnung in Weimar aufgezeichnet sind. (IV, 142ff.) Goethe, so lesen wir da, lobte ihn für seine Sappho. Er aber hatte an dem Lob

3 "Ich versank immer mehr in eine hypochondrische Stimmung [...]. Mir war damals zumute als ob ich nie mehr etwas schreiben würde. Dazu traten noch in Verwirrung gekommene Herzensangelegenheiten. Ich beschlo $B$ dem Zustande durch eine Reise ein Ende zu machen." (Franz Grillparzer, Sämtliche Werke. Ausgewählte Briefe, Gespräche, Berichte. Hrsg. von Peter Frank und Karl Pörnbacher. München 196065 , Bd. IV, S. 130-131. Die Ausgabe ist im folgenden nur noch nach Band und Seitenzahl zitiert.) 
keine ungeteilte Freude, handelte es sich doch in seinen Augen weitgehend um ein Selbstlob Goethes, weil er beim Schreiben der Sappho "so ziemlich mit [Goethes] Kalbe" gepflügt, also im Stile Goethes gedichtet hatte. Die Einschränkung der viel zitierten Wendung durch die Worte "so ziemlich" läßt vermuten, daß er Goethes Lob als herablassend empfand, da nach seiner eigenen Einschätzung der Abstand zwischen Sappho und Iphigenie keineswegs einfach seinem Zurückbleiben hinter dem Ideal zu verdanken war. Schon in einer Tagebuchnotiz von 1817 hatte er "um alles in der Welt keine der schönen Reden in Tasso und Iphigenia vermissen" wollen - und dann doch im selben Atemzug das gerade Bewunderte mit der Bemerkung kritisiert: "aber dramatisch ist es nicht." (III, 765) Entsprechend hat er auch an anderer Stelle wiederholt geäußert, Goethes Talent liege im Epischen, nicht im Dramatischen, und da er seine eigene Stärke im Dramatischen sah, hatte er hier den Punkt bezeichnet, an dem er gegenüber Goethe aus der Rolle des Epigonen herausfinden wollte. Von hier aus versteht man, warum ihn Goethes Lob der Sappho nicht freuen konnte: In seinen Augen erhöhte es ihn nicht zum Kollegen, sondern wies ihm die als erniedrigend empfundene Rolle des Epigonen zu. Wie unwohl er sich in dieser Rolle fühlte, ist an seiner Furcht abzulesen, mit dem so unvergleichlich arrivierteren Dichterkollegen "einen ganzen Abend allein zu sein". Eine entsprechende Einladung Goethes schlug er aus: ein deutliches Indiz seiner Befangenheit und seines Unterlegenheitsgefühls. Und doch auch zugleich des entgegengesetzten Willens zur Selbstbehauptung. Da Goethe ihn nämlich ausdrücklich an die Fruchtbarkeit seiner Freundschaft mit Schiller erinnert hatte, konnte sich der enttäuschte Grillparzer in seinen Ansprüchen und Zielen gleichwohl bestätigt fühlen. Es war deshalb keineswegs so, daß er sich einen solchen kollegialen Austausch nicht zugetraut hätte. Nur eben nicht im persönlichen Gespräch, ja, nicht einmal in Briefen, ${ }^{4}$ da er sich dem versierten Weltmann Goethe gesellschaftlich hoffnungslos unterlegen fühlte. Stattdessen konnte er allein auf literarischer Ebene hoffen, mit dem bewunderten Vorbild ein Verhältnis von Gleich zu Gleich zu erreichen.

Das schloß von seiner Seite von vornherein jede Kritik an Goethe aus, die nicht immer zugleich als Ausdruck seiner Liebe und Ehrfurcht gemeint gewesen wäre. ${ }^{5}$ Eben deshalb dürfte ihm mit Weh dem, der lügt! die befriedigendste Antwort an Goethe gelungen sein: befriedigend sowohl im Sinne künstlerischer Selbstbefreiung6 ${ }^{6}$ wie gleichzeitiger Bewährung von Ehrerbietung und Dank-

4 Bei seiner Rückkehr nach Wien beschloß er, "sogleich an ein neues dramatisches Werk zu gehen, das [er] statt eines langweiligen Verkehrs durch Briefe, Goethen zueignen wollte". (IV, 151)

5 Immer wieder finden sich in seiner Kritik an Goethe Beteuerungen, daß seine Äußerung nicht so verstanden werden dürfe, als wenn sich seine "Liebe und Ehrfurcht für ihn vermindert" hätte.

6 Richtig sieht Bruce Thompson (Franz Grillparzer. Boston 1981, S. 78) die 
barkeit gegenüber dem "allerdings Größten aller Deutschen"7, wie er ihn in Variationen immer neu zu nennen pflegte. In dem Verhältnis des Küchenjungen Leon zu Bischof Gregor ist sein Verhältnis zu Goethe lustspielhaft gespiegelt. Schon beim ersten Auftreten in seinem Garten ist der Bischof die zugleich ehrfurchtgebietende und rührende Vaterfigur ${ }^{8}$, als die Grillparzer Goethe in dessen Garten erlebt hatte, wie er mit ihm über Sappho sprach, ${ }^{9}$ und das Lustspiel

Dramen Der Traum ein Leben und Weh dem, der lügt! im Zusammenhang mit Grillparzers Versuch, sich von seiner akuten Niedergeschlagenheit ("despondency") in den sechziger Jahren zu befreien. Statt jedoch Goethes Bedeutung für Grillparzers persönliche Entwicklung in den Blick zu nehmen, stellt er Grillparzers Verhältnis zu Goethe nur in den allgemeinen Zusammenhang der GoetheRezeption des 19. Jahrhunderts, dem Goethes Bildungsideal ("the Goethean ideal of the education and fulfillment of the human personality in its totality") als überholtes Uberbleibsel des 18. Jahrhunderts erschien.

7 "Meine Erinnerungen an Feuchtersleben" (1850/51?), IV, 223. Selbst nach Goethes Tod schaffte Grillparzer es nicht, gegenüber Goethe ein unverkrampftes Verhältnis zu entwickeln. Wiederholt erklärte er sich selbst "für den besten, der nach ihm und Schiller gekommen" war (z.B. in der Selbstbiographie [IV, 150]), wobei der ambivalente Gebrauch der Präposition "nach" diese Aussage wieder doppelt verstehen läßt: im Sinne bescheidener Nachordnung wie selbstbewußter Gleich- oder sogar Höherstellung.

8 Das obige Zitat aus dem Tagebuch vom 25. Juni 1810, in dem es um Grillparzers Kampf gegen seine Anfälligkeit zur Melancholie geht, endet mit einem lateinischen Zitat, in dem er sich nicht als erwachsenen Mann, sondern als unfertigen Jungen sieht: "Hinaus in die Welt, um diesen Trübsinn, wenn auch nicht zu stillen, aber doch wenigstens zu übertäuben. Dormit puer, non mortuus est." Die gleiche Selbstcharakterisierung findet sich in seinem Bericht über die Begegnung mit Goethe: "Als es aber zu Tische ging und der Mann, der mir die Verkörperung der deutschen Poesie, der mir in der Entfernung und dem unermeßlichen Abstande beinahe zu einer mythischen Person geworden war, meine Hand ergriff um mich ins Speisezimmer zu führen, da kam einmal wieder der Knabe in mir zum Vorschein, und ich brach in Tränen aus." (IV, 146)

9 "Man wies mich [...] zu Goethe, der in seinem Hausgärtchen auf und nieder ging. Nun wurde mir die Ursache seiner steifen Körperhaltung gegenüber von Fremden klar. Das Alter war nicht spurlos an ihm vorübergegangen. Wie er so im Gärtchen hinschritt, bemerkte man wohl ein gedrücktes Vorneigen des Oberleibs mit Kopf und Nacken. Das wollte er nun vor Fremden verbergen und daher jenes gezwungene Emporrichten, das eine unangenehme Wirkung machte. Sein Anblick in dieser natürlichen Stellung, mit einem langen Hausrock bekleidet, ein kleines SchirmKäppchen auf den weißen Haaren hatte etwas unendlich Rührendes. Er sah halb wie ein König aus und halb wie ein Vater." Auch Gregor tritt in seinem Garten nicht etwa so aufrecht und "gehoben" auf, wie er offiziell "durch die Straßen" zu gehen pflegt (V, 43-46), sondern informell (Leon: "daß Gott! mit bloßem Haupt"), und 
endet, wie unten nachgewiesen werden soll, mit einer Rede des Bischofs, in der Grillparzer der Gestalt des späteren, ja, des spätesten Goethe Tribut gezollt hat. Doch getreu dem Vorsatz, den Dialog mit Goethe im Genre des Dramas zu suchen, antwortet Weh dem, der lügt! in erster Linie auf eines der Dramen, über die Grillparzer zu Goethe gefunden und mit denen er sich zuvor bereits in Sappho auseinandergesetzt hatte, ohne damals der Selbstverdächtigung des Epigonentums entgehen zu können: Iphigenie auf Tauris.

In Goethes Schauspiel leiden Iphigenie und ihr Bruder Orest an Melancholie, jedoch nicht in demselben Grad. Der schwerere Fall ist Orest, dem "eine Götterhand das Herz zusammendrückt", und zwar so heftig, daß es ihm, wie er sagt, leicht fiele, "dem schönen Licht der Sonne zu entsagen." 10 Eine ähnliche Aussage wäre von Iphigenie nicht zu erwarten. Auch sie fühlt sich vom gemeinsamen Familienfluch bedroht, aber wenn sie darüber auch in Gefahr gerät, ihren Glauben an die Güte der Götter zu verlieren, so wird sie davon doch nicht in Todessehnsucht getrieben. Sie schafft es, nicht nur sich selbst, sondern auch den Bruder von der Melancholie zu heilen, indem sie den eigenen Kummer über die Entfernung vom Land der Griechen in eine konkrete Hoffnung auf Heimkehr verwandelt. Das beginnt damit, daß sie schon vor der Wiederbegegnung mit dem Bruder ihrem traurigen Gruibeln eine positive Richtung gibt, indem sie sich Bilder Griechenlands vor Augen führt, die ausdrücklich in die Kindheit ihres Vaters und in ihre eigene Kindheit gehören, also lange hinter die Zeit zurückführen, in der sie der Vater für das Staatswohl hatte töten lassen wollen. In diesem Verfahren ist bereits ihre spätere These angedeutet, daß Heilung vom Atridenfluch nur durch Rückkehr in eine von Barbarei befreite Menschlichkeit zu erreichen sei. Indem sie ihre Bereitschaft zur Heimkehr von der Offenlegung ihrer Pläne gegenüber Thoas abhängig macht, wandelt sich ihre Melancholie in konkrete Zuversicht.

Der Melancholie Iphigenies entspricht im Lustspiel die Melancholie des Bischofs, die gleichfalls bereits im ersten Aufzug eingeführt und von dem an ihr leidenden auf ähnliche Weise kuriert wird. Bei seinem ersten Auftreten sehen wir ihn tief betrübt ("betrübt im Innern seiner Seele", V, 101), daß es ihm nicht gelungen ist, seinen Neffen Atalus aus der Sklaverei zu befreien. Ist dieser doch als Geisel in den Händen der Barbaren des Rheingaus, und sie behandeln die Geiseln als Sklaven, seitdem zwischen ihnen und den Franken, "durch Treubruch aufgestachelt" (V, 293), wieder Krieg ausgebrochen ist. ("Treubruch" gab es dabei

die Privatheit der Szene erlaubt es ihm, auch seinem persönlichen Kummer Ausdruck zu geben und sich erschöpft auf eine Rasenbank zu setzen.

10 II. 1, S. 17. (Iphigenie auf Tauris ist hier wie im folgenden nach dem 5. Band der Hamburger Ausgabe, 6. Aufl., 1962, zitiert.) 
von beiden Seiten, und beide Seiten halten sich an den Geiseln schadlos.) In dieser Situation versucht der Bischof, seinem eigenen Versagen und seinen Selbstzweifeln durch logische Fehleranalyse und entsprechende Fehlerbekämpfung beizukommen. Der Fehler, so findet er heraus, liegt einerseits bei ihm selbst, denn ohne seine stolze Lüge gegenüber dem König, er brauche kein Geld, wäre Atalus schon wieder frei. Andererseits ist die Schuld an des Neffen Gefangenschaft Angelegenheit der Gemeinschaft: ohne den Treubruch, der den Krieg wieder aufflammen ließ, wäre Atalus gar nicht erst von der Geisel zum Sklaven geworden. Die Lüge scheint mithin in der Rechnung des Bischofs zu einer allgemeinen Gewohnheit geworden, einem Laster, das dem Menschen gleichsam gattungsbildend anhaftet wie die Erbsünde, ihn selbst noch vom reißenden Raubtier negativ unterscheidend. Da aber die Geisel in den Augen des Bischofs das freiwillig gegebene Pfand für ein Versprechen war, das sich durch den erneuten Kriegsausbruch als unwahrhaftig erwiesen hat, will er mit dem neuen Befreiungsversuch auch jenen Teufelskreis der Lüge durchbrechen. Gleichzeitig erweitert sich seine Zielsetzung: Von nun an soll die physische Befreiung des Atalus, genau wie die Befreiungsaktion Iphigenies bei Goethe, zugleich ein wesentlicher Schritt zur Befreiung des Menschen überhaupt sein. ${ }^{11}$ Und wie bei Iphigenie hat sich auch seine Melancholie mit der Entdeckung des Heilmittels der Wahrhaftigkeit in ein neues Gottvertrauen gewandelt.

Bei Iphigenie handelt es sich freilich um einen längeren, nicht unkomplizierten ProzeB. In ihrer unbedingten Wahrheitsforderung gegenüber Orest und Pylades geht sie zunächst wie selbstverständlich davon aus, daß ihr die Wahrheit verfügbar ist; sind ihr doch Orests und Pylades' listige Befreiungspläne bekannt und kann sie in dieser Hinsicht gegenüber Thoas "Wahrheit" ohne Einschränkung als Offenheit üben. Dabei lernt sie jedoch bald, daß ihr Wahrhaftigkeitskonzept als solches nur begrenzt zur Gewinnung von Menschlichkeit taugt. Pylades erinnert sie an die Relevanz einer anderen Bedeutung von Wahrheit:

So wunderbar ist dies Geschlecht gebildet,

So vielfach ist's verschlungen und verknüpft,

$\mathrm{DaB}$ keiner in sich selbst, noch mit den andern

Sich rein und unverworren halten kann. (Auftritt IV,4)

Es ist diese Seite der Wahrheit, die Iphigenie im fünften Akt an sich selbst erfährt. Ihre Bedrängnis erklärt sich daraus, daß sie durch ihr rigoroses Wahrheitskonzept außer sich selbst auch den Bruder gefährdet. Sie fühlt sich da so in die Enge getrieben, daß sie auf den Gedanken verfällt, es sei vielleicht nur noch ein göttliches Wunder, das sie retten könne: "Was bleibt mir nun, mein Innres zu verteidgen? / Ruf ich die Göttin um ein Wunder an? / Ist keine Kraft in meiner

11 Der auf die ganze Menschheit gerichtete Blick des Bischofs ist im Lustspiel zusätzlich durch das frühmittelalterliche Verständnis des christlichen Missionsauftrags motiviert. 
Seele Tiefen?" (V. 1883-85) Und wenig später beantwortet sie ihre Fragen, indem sie tatsächlich die Götter um Hilfe anruft: "Wenn / Ihr wahrhaft seid, wie ihr gepriesen werdet, / So zeigts durch euern Beistand und verherrlicht / Durch mich die Wahrheit!" (V. 1916-19) Von einem Wunder ist da direkt nicht mehr die Rede, doch liegt es natürlich im Wesen des Gebets, die Lösung der Bedrängnis nicht auf natürlichem Wege, sondern eben durch göttliches Eingreifen zu erhoffen. In dieser Erwartungshaltung kann es ihr - und dem Zuschauer, und zwar wiederum ohne ausdrückliche Benennung - als göttliches Wunder erscheinen, wenn sie dann tatsåchlich die Kraft in ihrer Seele findet, Thoas die Wahrheit zu sagen. Weiter bewährt sich dieses Wunder darin, daß sich sowohl Thoas wie Orest von ihr zum Reden statt zum Kämpfen überreden lassen. Orest mit der ausdrücklichen, uns an ihr voriges Gebet erinnernden Erklärung, sie müßten harren, "welch Ende / Die Götter unsern Taten zubereiten." (V. 2025/26) Und das göttliche Wunder bewährt sich weiter darin, daß Thoas die Identität des Orest akzeptiert und Orest (in seiner neuen Offenheit für die Offenbarung des Willens der Götter) zu seiner neuen Deutung des Orakelspruchs findet: Aufgegeben war ihm nicht, aus Tauris das Bild der Artemis, also der Schwester des Apollo, sondern seine eigene Schwester Iphigenie zu befreien. Auch Thoas zeigt die erhoffte Einsicht und läßt sich von Iphigenie an sein "Wort" erinnern, das er ihr gegeben hatte und dessen Erfüllung sie nun nicht mehr wie zuvor im Sinne einer aus dem Schwur folgenden Rechtsverpflichtung von ihm einfordert, sondern als Gelegenheit zur "edlen Tat". Da diese Gelegenheit in ihren Augen zugleich die stärkste Verpflichtung überhaupt ist, kann sie ihrer Mahnung an Thoas in der letzten Szene, genau wie vorher ihrem Gebet an die Götter, wieder den Nachdruck geben, der im Ton fast an moralische Erpressung erinnert: "Versagen kannnst du's nicht, / Gewähr es bald!" Thoas freilich akzeptiert zwar die Verpflichtung, bleibt jedoch innerlich verletzt, was wiederum sie verletzt. So besteht der letzte Teil des Wunders darin, daß sie ihn mit ihren Schlußworten versöhnen und seine Bitternis heilen kann: eine Heilung, die sich in seiner Befähigung ausdrückt, ihr sein "Lebt wohl!" zu schenken und damit sie zu heilen. Eine Heilung zwar in einem immer noch nicht abgeschlossenen und nicht abzuschließenden Sinne, denn der Schmerz im Gedanken an Thoas wird bleiben. Die Tränen aber werden "lindernder" fließen.

Das zunächst so einfach aussehende Lösungskonzept Iphigenies, ihre moralische Forderung der Wahrhaftigkeit, wird also im Laufe des Dramas modifiziert. Ihr Glaube an die Wahrhaftigkeit und der Glaube an die Götter erweisen sich als zwei wechselseitig von einander abhängige Bedingungen ihres Erfolgs, und von einem Erfolg kann am Ende nur in einem eingeschränkten, relativen Sinn die Rede sein. Um einen Erfolg aber handelt es sich gleichwohl, und zwar so sehr, daß Goethe selbst sein Iphigenie-Drama nicht mehr wie Euripides als Tragödie, sondern als Schauspiel bezeichnen wollte. Doch war das Glück, das Iphigenie mit ihrem Wahrheitskonzept hatte, in den Augen Grillparzers offenbar zuletzt weder nur die Frucht ihres Mutes noch ihres Gottvertrauens, sondern beruhte in beidem vor allem auf Goethes dramaturgischer Versuchsanordnung. Grillparzer hat sie umgedreht: Während Iphigenie im Laufe des Stücks dazu gebracht wird, das 
Wahrheitsgebot als Bedingung wahrer Menschlichkeit zu verstehen und durchzusetzen, durchläuft Gregor einen umgekehrten Lernprozeß. Wird Iphigenie erst im Laufe des Stückes zur Heroin der Wahrheit, so ringt sich Gregor gleich zu Beginn zu missionarischem Wahrheitsfanatismus durch, während er am Ende seine Meinung geändert hat: Die Lüge ist nicht ausrottbar (V, 1800-07), hat vielmehr ihren notwendigen Platz in Gottes Schöpfung. (V, 1817-21). Der LernprozeB erbringt bei Gregor also in Wahrheit keinen Lernfortschritt. Er bringt es fertig, die Absage an seinen vorigen Wahrheitsfanatismus ebenso wie diesen selbst als Ausdruck seines Gottvertrauens anzusehen, und ganz offensichtlich erliegt er in seiner theologischen Einschätzung der Rolle der Wahrheit hier wie dort einem Selbstbetrug.

Dabei hat Grillparzer den schroffen Rigorismus des Bischofs zu Beginn des Stücks durch einen Zug zur Bescheidenheit, ja, zur Selbstdemütigung, abgemildert. Der Bischof ist mithin alles andere als eine billige Karikatur der Iphigenie-Rolle. Der Bibelvers, über den er seine nächste Predigt vorbereitet ("Dein Wort soll aber sein: Ja, ja; nein, nein.") führt ihn zu der Einsicht, daß er gegen das Wahrheits-Gebot verstoßen hat, als er ein Angebot des Königs auf eine Geldzuwendung aus Stolz als unnötig zurückwies, obwohl er das Geld als Lösegeld für seinen Neffen dringend benötigt hätte. Im Unterschied zu Iphigenie sieht er sich also nicht nur als Opfer der Schuld anderer, sondern selbst schuldig geworden. Und als Leon sich dann anbietet, ihm den Neffen herbeizuschaffen, nimmt er das Angebot nur unter der Bedingung an, daß die Befreiung unter keinen Umständen durch Betrug zustande kommen dürfe. Der Ton moralischer Unbedingtheit, mit dem er in seinem Auftrag an Leon den gerade bedachten Bibelvers mit seiner eigenen Formel "Weh dem, der lügt!" variiert, ist also nicht etwa nur bischöfliches Amtsgehabe, sondern folgt aus seinem unbedingten Willen, sich selbst zu bessern. Der Selbstdemütigung dient schon die bloße Bereitschaft, nunmehr von einem Küchenjungen die Hilfe anzunehmen, die er vom König nicht annehmen wollte. Genauso ist sein plötzlich verändertes Verhältnis zu dem Geld zu verstehen, das er sich vom Munde abgespart hatte, um den Loskauf des Neffen auch ohne die Hilfe des Königs zu erreichen. Statt es Leon mitzugeben, will er es nun lieber an die Armen verteilen, um nichts mehr von seiner eigenen Leistung, sondern alles von der Güte Gottes hoffen zu können. Der Selbstbetrug folgt also tatsächlich ausgerechnet aus seiner Absicht der Selbstbesserung.

Gleichzeitig zeigt aber seine rigorose Absicht der Beförderung der Menschlichkeit, ohne daß er es merkt, einen Rückfall in genau jene Barbarei, die er bekämpfen möchte. Während Iphigenie mit der Gefahr eines solchen Rückfalls in die Barbarei nur gedanklich in Berührung kommt, greifbar vor allem in ihrem Zitat des Lieds der Parzen, manifestiert sich die barbarische Seite des Bischofs auf groteske Weise ausgerechnet in seinen religiös-moralischen Erbauungsversuchen, mit denen er Leon traktiert. Bedenkenlos ist er bereit, seinen Wahrheitsprinzipien das Leben des Neffen zu opfern - eine Barbarei, deren ebenso mörderische wie selbstmörderische Potenz bis in die Kälte des Tons hinein zu spüren ist. Als Leon ihn auf die Gefahren eines Betrugsverzichts für Atalus hinweist, fährt es ebenso 
überheblich wie abfällig aus Gregor heraus: "So mag er sterben und ich sterbe mit." (V, 345)

$\mathrm{DaB}$ es dazu nicht kommt, der Bischof also weder Atalus noch sich selbst zum Blutmärtyrer macht, sondern am Ende den befreiten Atalus in die Arme schließen kann, hat nichts mit moralischen Lemprozessen im Sinne intellektueller Denkfortschritte zu tun, die das Lustspiel dem Bischof abverlangen würde. Weh dem, der lügt! ist alles andere als eine primitive Aufklärungskomödie. Genauso wenig aber geht es da um komplexe geistig-seelische Entwicklungsprozesse der Art, wie sie Iphigenie an sich erfährt und erfolgreich auch bei ihren Mitmenschen initiiert. Für Grillparzer gehörte das zur "Bildungs"-Dichtung, die er ablehnte. ${ }^{12}$ Zwar verehrte er Goethe wegen seiner Fähigkeit, sich im Unterschied zu Schiller, aber wie Shakespeare oder Euripides, "in die innerste Natur des Darzustellenden [sc. des darzustellenden Charakters] hineinzusetzen." (III, 706) Was ihn jedoch bei Goethe störte, war der Versuch, das Drama als Mittel zur Bildung des Charakters bzw. der "Seele"13 einzusetzen.

Anders als Iphigenie ist denn auch der Bischof mit seinen Erziehungsversuchen überhaupt nur im ersten und im letzten Akt auf der Bühne. Nicht so dagegen die eigentliche Hauptfigur des Lustspiels, der Küchenjunge Leon, den der Bischof belehren und bessern möchte, um gleichsam in den moralischen Fortschritten dieses Schafes seiner Herde die eigenen Seelenfortschritte zu objektivieren und zu verallgemeinern. Leons Verhältnis zum Bischof ist allerdings ăhnlich kompliziert wie das Verhältnis Grillparzers zu Goethe, und Leon reagiert darauf wurde schon hingewiesen - auf die moralische Autorität des Bischofs ebenso mit "Melancholie" wie Grillparzer auf die künstlerische Autorität Goethes. $\mathrm{Da}$ das Motiv der Melancholie zugleich das tertium comparationis zwischen Goethes Iphigenie-Drama und Grillparzers Lustspiel ist, bedarf es in diesem Punkt nun der genaueren Analyse der Gestalt des Leon. Dabei kommt es darauf an zu zeigen, daß Leons Seelenprobleme tiefer gehen als die des Bischofs und der Goetheschen Iphigenie.

Leons Melancholie scheint am Anfang von Orests Todessehnsucht weit entfernt, doch enthüllt dann die Handlung, wie ich zu zeigen hoffe, mehr und mehr das Ausmaß der Parallele. Als er das erste Mal auftritt, zeigt er sich verstört und verzweifelt über den Bischof, dessen Hungerstreik ihn so sehr in seiner Berufsehre kränkt. Seine Enttäuschung ist so groß, weil sein Bild des Bischofs schon zu Beginn gerade so erhaben ist wie in Goethes Schauspiel das Bild ${ }^{14}$, das sich Orest

12 Uber die Zeit nach seinem Deutschlandaufenthalt schreibt er, er sei schon damals "kein Freund der neueren Bildungsdichter" gewesen, "selbst Schiller und Goethe mitgerechnet." (IV, 163)

13 "Der Mittelpunkt des menschlichen Wesens, sinnlichen und geistigen ist die Seele. In ihr liegt alles vereinigt und aufbewahrt: Erfahrenes, Erlebtes, Gedachtes, Gefühltes. Dieser Zuwachs ist was man Bildung nennt. Er ändert in einem gewissen Grade selbst die Substanz der Seele und durch ihn ist der Mensch im vierzigsten Jahre ein anderer als im vierten." (III, 226/27)

14 Hier liegt bekanntlich ein wichtiger Unterschied von Goethes Schauspiel gegen- 
in seiner Neuinterpretation des Apollinischen Orakels erst im Verlauf des Stücks von Iphigenie macht: Leon sieht im Bischof den lebendigen Garanten seines guten Geschicks und verehrt ihn wie ein wunderwirkendes Bild von göttlicher Segensund Heilkraft. Trotz dieser besonderen persönlichen Beziehung steht die Heftigkeit der Reaktion ("daß ich wahrlich nicht mehr kann"), mit der er auf das scheinbar knauserige Fasten des Bischofs reagiert, in keinem vernünftigen Verhältnis zum Anlaß. Vielmehr liefert sein Entschluß, dem Bischof den Dienst aufzukündigen, bereits den ersten Anhaltspunkt für einen akuten Ausbruch von Melancholie. Seine Vorstellung, Ortsveränderung werde ihm zu einer Besserung seiner Verhältnisse verhelfen, ist offenbar nur eine Variante der früheren, dem Stück vorausliegenden Entscheidung, sein Leben durch Eintritt in die Dienste des vorbildhaften Bischofs zu verbessern. Sobald er die Ortsveränderung durchgesetzt hat, kann das Bild des Bischofs nach demselben Schema umgekehrt wieder dazu dienen, ihn zur Rückkehr anzuspornen. Womit dasselbe Spiel wieder von vorne beginnen kann, da er, kaum nach Hause zurückgekehrt, aus Kummer über die scheinbar an Atalus verlorene Geliebte erneut auf den Ausweg der Ortsveränderung verfällt: "Ich nahe denn, um Urlaub zu begehren." (V, 1780) Die Begründung ist vielleicht einsichtiger als zu Beginn des Stücks, doch hat sich inzwischen im vierten Aufzug seine Sehnsucht nach Orstveränderung auch ohne einen vergleichbaren Grund wirklich bis zur Todessehnsucht gesteigert. Ich werde im einzelnen darauf zurückkommen. Soviel ist aber auch hier schon deutlich, daß Leons Melancholie durch Iphigenies Therapie einer auf Wahrhaftigkeit gegründeten Heimkehr in die Menschlichkeit, wie sie der Bischof für sich selbst wie den Rest der Welt adaptieren möchte, nicht zu heilen ist.

Aus Iphigenie war in diesem Punkt für Grillparzer nichts zu gewinnen. Während aber Goethe sein Seelendrama Iphigenie später selbst als "verteufelt human" kritisiert hatte, worüber sich Grillparzer noch im Jahre 1840 als über die beste Kritik an Iphigenie überhaupt freute (III, 772), war Faust von vornherein über solche Kritik erhaben. Bereits im Faust scheint der späte Satz aus Maximen und Reflexionen beherzigt, der sich wie eine indirekte Selbstkritik der Iphigenie lesen läßt: "Wäre es Gott darum zu tun gewesen, daß die Menschen in der Wahrheit leben und handeln sollten, so hätte er seine Einrichtung anders machen müssen. ${ }^{15}$ Es ist deshalb nicht zu verwundern, daß Grillparzer im ersten Aufzug von Weh dem, der lügt! dramaturgisch jene Mittel von Vertrag und Wette variiert hat, deren Verwendung bereits im Faust für ironische Relativierung des in der Iphigenie absolut gesetzten Wahrheitsthemas sorgt. ${ }^{16}$ Leon versteht des Bischofs Reiseerlaubnis, und damit die von ihr erhoffte Lösung seiner Probleme, sozusagen als Leistung für versprochene Gegenleistung, und diese besteht, als

über Racines Iphigenien-Drama, in dem die Befreiung Iphigenies zwar auch schon durch die Aufklärung eines Verwechslungsirtums zustande gekommen war, jedoch ohne Konsequenzen für das Bild, das die Akteure und die Zuschauer von der Heldin haben.

15 Maximen und Reflexiorien, 835.

16 Grillparzer schätzte Faust I dramaturgisch mehr als Faust II. 
Bedingung der Leistung, für ihn darin, daß er Atalus ohne Lug und Trug befreien wird: "Topp! Herr, auf die Bedingung." Erst nachdem er eingeschlagen und die Bedingung akzeptiert hat, kommen ihm Zweifel an der Erfüllbarkeit des Vertrags: "Aber seht, / Wenn nicht ein bißchen Trug uns helfen soll, was hilft denn sonst?" Des Bischofs Antwort, daß statt des Einsatzes von Lügen Gottvertrauen helfen müsse, nimmt von der vorigen Bedingung nichts zurück, verspricht dafür aber ein Mittel ihrer Erfüllung. ${ }^{17}$ Aus dem "Nur wenn du Atalus ohne Lüge befreist, kannst du dir und mir helfen," ist geworden: "Wenn du Gott vertraust, kannst du Atalus ohne Lüge befreien." Zugleich hat sich, auch ohne daß Leon da weiter nachfragt, an dieser Stelle der Vertrag, der Sache nach, in eine Art unausgesprochener Wette verwandelt, in der die Wetten des Faust-Dramas komisch abgewandelt scheinen. $\mathrm{Zu}$ einem formellen Wettangebot, nicht nur ins Gesicht des Bischofs, sondern auch vor sich selbst, fehlt Leon aus einsichtigen Gründen der Mut. Eine Wette, in der er ausdrücklich auf seinem Zweifel beharren wollte, müßte seinen Mangel an eben dem Gottvertrauen demonstrieren, das gerade erst Zusatzbedingung seines Fortgehens geworden war, und den Vertrag will er ja, wenn das nur überhaupt geht, durchaus erfüllen. Wettet Faust, daß er nie zum vollen Genuß des vollen Glücks betrogen werden könne, so zweifelt Leon, daß er Atalus ohne Lügen befreien werde. Indem der Bischof diesem Zweifel seinen Glauben an das moralische Potential Leons entgegensetzt, spielt er die Rolle, die im Faust Gott zukommt, als dessen Stellvertreter er im Lustspiel agiert. Die Differenz zu Gott zeigt sich darin, daß er das Wahrheitsgebot für Leon absolut setzt. Im übrigen aber folgt der Bischof dem Vorbild des Herrn, indem er die weitere Aktion ganz der Findigkeit Leons überläßt und sich bis zum Ende, das über den Ausgang der Wette entscheiden muß, aus der Handlung zurückzieht. ${ }^{18}$

$\mathrm{Da}$ er die Realisierung der Wette Leon überlassen hat, muß dieser vom zweiten bis vierten Akt außer seiner Orest-Rolle auch die Rolle Iphigenies mitübernehmen und für eine Befreiungsaktion ohne Lügeneinsatz kämpfen. Und weil Grillparzer das Seelendrama Iphigenies als undramatisch kritisierte, mußte er, Grillparzer, sich folgerichtig für den zweiten bis vierten Aufzug eine völlig neue Dramaturgie ausdenken. Sollte die Faust-Parallele von Kontrakt und Wette weiterhelfen, so lag es nahe, für Leon eine Gegenfigur zu finden, die ihm gegenüber eine

17 Der von Renate Delphendahl (Grillparzer. Lüge und Wahrheit in Wort und Bild. Bern 1975, S. 20) aufgestellte Satz, die "christliche Glaubensüberzeugung des Bischofs" sei "kongruent mit dem Glauben an das Gute im Menschen", bedarf also der Qualifizierung. Des Bischofs Glaube an das Gute im Menschen ist von seinem Glauben an Gott nicht zu trennen.

Dagmar C. Lorenz (Grillparzer. Dichter des sozialen Konflikts. Wien, Köln, Graz 1986, S. 90) sieht das Verhalten des Bischofs "mit der Klassenfrage verquickt": "Nicht jeder kann sich die Wahrheit leisten. Die Ehrlichkeit im Sinne des Bischofs ist nur den Privilegierten, wie ihm selbst, verfügbar, da andere für ihn tun, wovor er aufgrund seiner Position geschützt bleibt." Die Wirkung des Lustspiels beruht freilich zu einem guten Teil darauf, daB auch dem Bischof die Wahrheit nur begrenzt verfügbar ist. 
ähnliche Versucher-Rolle zu spielen hatte wie Mephisto gegenüber Faust. Während Iphigenie in Thoas keinen wirklichen Gegenspieler hat (und zwar weniger wegen seiner in ihm bereits angelegten Neigung zur Humanität, als wegen ihrer eigenen Immunität gegen seine Liebe), hat Grillparzer Leon in Edrita eine Partnerin zur Seite gegeben, die in ihm genuine Liebe erweckt und eben damit, was seine unausgesprochene Wette mit dem Bischof und mit Gott anlangt, als seine Versucherin fungieren kann.

Bevor ich das im folgenden genauer belege und dann später auch wieder auf Faust zurückkomme, bleibt noch eine weitere Voraussetzung zu klären. In einem Brief an den Grafen Brühl aus dem Jahre 1821 hatte Grillparzer im Blick auf Das goldene Vließ erklärt, Goethes Dramaturgie sei im Falle der "ruhig schreitenden Iphigenie" erfolgreich gewesen, für "reichere und bewegtere Stoffe des Altertums" jedoch ungeeignet. (IV, 765f.) Weh dem, der lügt! zeigt, daß er nun auch in seiner Wiederaufnahme des Iphigenie-Stoffes dramaturgisch hinter das Konzept des Goetheschen Seelendramas auf dessen Modell, die Euripideische Iphigenie bei den Taurern, zurückgegriffen hat. Diese Tragödie lieferte ihm Anregungen für sein Lustspiel genau da, wo Goethe in seinem Schauspiel über sein Modell hatte hinauskommen wollen: in der Vorrangstellung der technischen Probleme vor den moralischen.

\section{III}

Die Tragödie des Euripides hat von ihrem Plot her zwei Teile. Im ersten geht es um die wechselseitige Wiedererkennung der beiden Geschwister Iphigenie und Orest, im zweiten um die Befreiungsaktion. Dabei lebt der erste Teil dramaturgisch von der zeitlichen Differenz zwischen der äußerlich-faktischen Begegnung und ihrer Realisierung im Bewußtsein der Geschwister. Immer wieder neu geraten sie in melodramatische Gefahr: sie, daß sie ihn unwissentlich tötet, und er, daß er sich unwissentlich von ihr töten lassen will. Entsprechend den Erfordernissen seiner Lustspielfabel hat Grillparzer dieses Schema der wechselseitigen Verkennungen der Geschwister für die Dramaturgie des Liebesverhältnisses zwischen Leon und Edrita genutzt, und zwar für das Stück insgesamt, also nicht nur für die erste Hälfte. Obwohl die beiden sich schon im zweiten Aufzug bei ihrer ersten Begegnung ineinander verlieben, wagen sie es nicht, sich ihre Liebe bewußt zu machen, und auch Edrita weiß erst im fünften Aufzug, daß sie Leon gegen seinen Willen gefolgt ist, um sich von ihm zu ihrer Liebe befreien zu lassen. Bis sie im fünften Aufzug bereit sind, einander und sich selbst ihre Liebe zu bekennen, kommt es im Lustspiel zu ebenso komischen gegenseitigen Gefährdungen ihres Verhältnisses wie in der Tragödie des Euripides zu tragisch-melodramatischen.

Wichtiger ist jene andere, bereits angekündigte Parallele, die darin besteht, daß der zweite Teil der Tragödie seine dramatische Spannung aus der Differenz zwischen den gedanklichen und den technischen Schwierigkeiten der Befreiungs- 
aktion gewinnt. Iphigenie fragt sich, wie sie die Befreiungsaktion gegen den Willen der Götter zustande bringen kann. Oder zumindest, da die Götter sich untereinander uneins scheinen, gegen den Willen der einen Göttin Artemis, deren Priesterin sie ist. Orest scheint eine Lösung zu wissen: Apollo könne unmöglich die Entführung des Götterbildes befohlen haben, wenn dies nicht zugleich im Sinne der Artemis selber wäre. Doch deutlich hat Euripides sich bemüht, dieses Argument durch den dramatischen Fortschritt der Handlung als allzu simpel zu denunzieren. Je mehr er dafür sorgt, daß die Akteure erst einmal in Sicherheit gewiegt werden, sie könnten ihre Pläne unbehelligt durchführen, desto tragischer scheint dann die Katastrophe über sie hereinzubrechen. So leicht sich also Thoas zunächst auch täuschen läßt, so wenig ist den Griechen damit die Flucht schon geglückt. Sie geraten vielmehr am Meer in schier aussichtslose Kämpfe mit den Leuten des Thoas, noch ehe der ihren Verrat durchschaut und sich zu ihrer Verfolgung auf den Weg macht. Obwohl sie es schließlich bis aufs Schiff geschafft haben, scheint ihr Schicksal besiegelt, weil sich nun auch noch die Naturgewalten gegen sie verbünden. Das Meer wirft ihr Schiff immer wieder an den Strand, so daß sie nicht fortsegeln können und eine leichte Beute der Taurer werden müssen, wenn Thoas in den Kampf eingreift. Iphigenies Anrufung der Artemis bleibt ohne Folgen, und Orests Ableitung, die Entführung des Bildes könne nicht gegen die Absicht der Artemis befohlen worden sein, erscheint nun im nachhinein nichts als ein frommer Wunsch: ebenso realitätsfern wie die frommen Gebete der Iphigenie. Erst ganz am Ende nehmen die Ereignisse eine positive Wendung: durch das wunderbare Eingreifen der Göttin Athene, die Euripides bekanntlich so unverhohlen als dea ex machina auftreten läßt, wie das von den griechischen Klassikem niemand außer ihm fertig gebracht hat. Während das Wunder der göttlichen Epiphanie als theatralische Lösung vom frommen Mythos vorgegeben war, bestand die Leistung des Euripides im Vergleich zu seinen beiden älteren Kollegen Aischylos und Sophokles, wie schon Aristoteles betont hat, in der dramatischen Steigerung der Handlung ins aussichtslos Tragische. Das Wunder der Gotteserscheinung hebt die Tragik nicht auf, sondern macht sie umso fühlbarer.

Dadurch, daß Grillparzer die Handlung von Weh dem, der lügt!, der Erzählung des Bischofs von Tours folgend, ins frühe Mittelalter legte, konnte er die für die Euripideische Tragödie so wichtige Gotteserscheinung in mittelalterlicher Verwandlung in sein Lustspiel einbringen. Nämlich so: Als Leon nicht einzusehen vermag, was ihm denn bei der Befreiung des Atalus helfen könne, wenn nicht "ein bißchen Trug", weist der Bischof diesen Mangel an moralischem Ernst empört zurück und blitzt ihn an: "Gott! Mein, dein, aller Gott!" (V. 379) Leon glaubt, einen wirklichen Blitz gesehen zu haben: "Es blitzte." (V. 380) Der Bischof aber fühlt sich von diesem Glauben sogleich zu einer theologischen Auslegung ermuntert, mit der er seine Ermahnung zur Wahrheit stützen kann. Gott selbst 
Im Innern hat des Guten Geist geleuchtet, Der Geist des Argen fiel vor seinem Blitz.

Was dir in diesem Augenblicke recht erscheint,

Das tu! Und sei dir selber treu und Gott.

Weh dem, der lügt!

Aus der Wundererscheinung, die für den frommen Bischof nichts Aufregendes hat, und der von ihm gebotenen Erklärung schließt Leon wie folgt: Da er Atalus nicht ohne Betrug befreien kann, ist die einzige Lösung, daß Gott ihm, wenn er Betrug zu vermeiden sucht, mit Wundern zu Hilfe kommen wird. So geht von nun an sein Glaube (und Unglaube) an sich selbst zusammen mit der Gewißheit (und Ungewißheit), in seiner Wundergläubigkeit ${ }^{19}$ den Geist des Guten auf seiner Seite zu haben, während ihm der Zweifel an der Realisierung des Wunders mit dem "Geist des Argen" zusammenfällt. Und wie könnte Gott nicht Wort halten? Wollte er das Wunder versagen, wäre er nicht der Geist des Guten, sondern des Argen. Dennoch ist Leon auf diese Weise in eine Zwickmühle geraten. Er könnte sie zwar dadurch lösen, daß er Gregors Bedingung des Lügenverzichts für weniger wichtig ansähe als die andere des Gottvertrauens. Das Gottvertrauen würde dann für ihn nichts anderes besagen, als daß Gott, eben weil er Wunder vollbringen kann, das Unmögliche möglich machen und Leon auch dann helfen wird, wenn dieser die Bedingung des Lügenverzichts nicht erfüllen kann. ${ }^{20}$ So einfach aber will Leon es sich nicht machen. Er kann die Last nicht einfach von sich auf Gott abschieben, und zwar deshalb nicht, weil es sonst auf seine eigene Leistung nicht

19 Schon Rolf Geißler (Ein Dichter der letzten Dinge. Grillparzer heute. Subjektivismuskritik im dramatischen Werk - mit einem Anhang über die Struktur seines politischen Denkens. Wien 1987, S. 75 und 78) wertet die Wirkung der Blitzerscheinung auf Leon als "Saulus-Paulus-Phänomen", das ihm dazu verhelfe, Edritas Schlüsselhilfe, ihre Spurenverwischung, den Positionswechsel des Fährmanns und die christliche Rückeroberung von Metz als Wundertaten Gottes zu deuten. Nach Geißler erfüllt Edrita mit ihrem selbstlosen Handeln "das Wort aus Goethes Iphigenie (IV, 2), daß Götter 'Menschen menschlich zu erretten' pflegen, daß also die Wahrheit der Legende auch eine Lebenswirklichkeit sein kann." (S. 79) Freilich ist die Hauptfigur des Lustspiels nicht Edrita, sondern Leon, und es ist seine Wundergläubigkeit, die als Lustspiel-Pendant zu derjenigen Iphigenies anzusehen ist.

Vgl. Grillparzers Notizen vom April 1837: "Wie? wenn mehr der Himmel dafür sorgte, daß nicht gelogen wird, als daß es aus freiem Entschluß hervorginge.

Wunder! Wunder! Wunder [!]

$\mathrm{Da} B$ etwa Gott selbst die gesagte Lüge zur Wahrheit machte." (Dichter über ihre Dichtungen. Franz Grillparzer. Hrsg. von Karl Pörnbacher. München 1970, S. 205.) 
mehr ankäme. Weil er an ihr festhält, solange es geht, vermeidet er es bis zum fünften Aufzug, das Wort "Wunder" überhaupt zu gebrauchen. Erst als er absolut keinen anderen Ausweg mehr sieht, beruft er sich auf das "Wunder", das Gott ihm nach seiner festen Überzeugung in jenem Blitz versprochen hat. Doch spielt die Idee des Wunders, auch wenn das Wort nicht fällt, vom Beginn der eigentlichen Befreiungsaktion bis zum fünften Aufzug überall die dramaturgisch entscheidende Rolle: Seit der Offenbarungsszene äußert sich Leons Gottvertrauen als Wunderglaube, und zwar so, daß dieser immer zugleich mit seinem Glauben an die Notwendigkeit und Möglichkeit der Selbsthilfe konkurriert.

Das beginnt am Ende des ersten Aufzugs, als Leon überraschenderweise den Auftrag des Bischofs ausführt, das für den Loskauf des Atalus gesparte Geld an die Armen zu verteilen. Wie anders als durch ein Wunder, so fragt sich der Zuschauer verblüfft, soll Leon es tatsächlich schaffen, Atalus zu befreien, wenn er in seinem naiven Gottvertrauen sogar auf die immerhin vorhandenen menschlichen Mittel verzichtet und das vom Bischof zum Freikauf zusammengesparte Geld auftragsgemäß unter die Armen und Kranken verteilt? Zu Beginn des zweiten Aufzugs zeigt sich dann aber, daß Leons frohgemuter Verzicht auf das Geld keineswegs als Beweis seines unbedingten Gottvertrauens dienen kann. Bringt er es doch spielend fertig, Geld sozusagen in einer eigenen creatio ex nihilo selbst zu schöpfen, indem er sich von dem mitreisenden Pilger als Sklave an Kattwald verkaufen läßt. Entsprechendes Oberwasser hat er, genau wie Orest und Iphigenie zu Beginn ihrer Befreiungsaktion bei Euripides, im ganzen zweiten Aufzug, wo er durch seinen Witz, in der doppelten Bedeutung von Scharfsinn und Wortgewandtheit, denen überlegen ist, die seinem Unternehmen entgegenstehen: dem Grafen Kattwald, in dessen Gewalt sich Atalus befindet, und auch dem Atalus selbst, der ihm die Kooperation bei der Fluchtplanung versagt. Im zweiten Aufzug also fallen seine eigenen Leistungen so wunderbar glücklich aus, daß es eines göttlichen Wunders nicht zu bedürfen scheint.

Allerdings sucht er da jeweils sein Wahrhaftigkeitsversprechen nur formal einzuhalten, während er es faktisch laufend bricht. Während er dieses Problem im ganzen zweiten Aufzug durch äußere Frische und Lustigkeit überspielen kann, tritt im dritten Aufzug an die Stelle der bisherigen forcierten Lustigkeit mehr und mehr etwas Gehetztes, das sich vorrangig aus den plötzlich massierten technischen Schwierigkeiten erklärt, zu deren Lösung die intellektuelle Überlegenheit seines Sprachwitzes nicht mehr ausreicht. Dabei hat Grillparzer an dieser Stelle für das aus der Euripideischen Tragödie übernommene Technik-Argument, also für die Betonung der Wichtigkeit der technischen Fluchtmittel, die dem Märchen verpflichtete Komödientradition des Wiener Volkstheaters ${ }^{21}$ nutzbar gemacht. Leon,

21 Nach Zdenko Skreb (Grillparzer. Eine Einführung in das dramatische Werk. Kronberg/Ts. 1976, S. 204) weist das Lustspsiel Weh dem, der lügt! "keinerlei 
von dem plötzlich die Steigerung vom Worthelden zum wirklichen Helden gefordert wird, ist da in die alptraumhafte Märchensituation des Abenteurers versetzt, der zur Erlangung seiner Zwecke schier übermenschliche Aufgaben vollbringen muß. Seine Aufgabe, den für die Flucht nötigen Schlüssel aus dem Schlafzimmer des schlafenden Kattwald zu stehlen, erinnert an das Märchenmotiv des Helden, der einen bestimmten Gegenstand aus der Höhle eines Ungeheuers stehlen muß. Stilgerecht nennt Leon den Vater Edritas bei dieser Gelegenheit einen Werwolf. (V, 1045) Der Held kann sich seine Aufgabe zwar dadurch erleichtern, daß er wartet, bis das Ungeheuer schläft; doch wird das Unternehmen dadurch auch wieder umso spannender, weil die Gefahr besteht, daß das Ungeheuer aufwacht. Entsprechend der Steigerung des Schwierigkeitsgrads seiner Aufgabe - dem schlafenden Werwolf konkret den Schlüssel zu entwenden, ist schwieriger, als ihn mit der Wahrheit zu belügen - herrscht im dritten Aufzug statt des Wortwitzes, zu dessen Opfer immer die anderen wurden, nunmehr der Situationswitz vor, als dessen Opfer in erster Linie er selbst erscheint. Seine Handlungen sind zunehmend konfus, nicht das Produkt überlegenen Durchblicks, sondern vom Augenblick eingegebene letzte Notlösungen. Wenn er schließlich, als Kattwald aufwacht, den gerade eroberten Schlüssel wegwirft, um ihn pfiffig dort zu suchen, wo er ihn nicht hingeworfen hat, dann kann er damit den Alten nur kurzfristig von seiner mörderischen Wut ablenken. Nur dadurch, daß sich Edrita als sein guter Geist erweist, da sie den Schlüssel heimlich durch den Schlafzimmerschlüssel ersetzt, entgeht er schließlich der Rache des Alten. In die Ecke getrieben, bleibt ihm zuletzt nichts übrig, als den weggeworfenen Schlüssel, bzw. den, den er dafür hält, zu "finden" und an Kattwald auszuhändigen. $\mathrm{Daß}$ er zu diesem lebensrettenden Einlenken bereit ist, verdankt er jedoch einzig dem Schlüsseltausch Edritas. Er bemerkt nämlich, daß der Schlüssel zu leicht ist, und reagiert, wie sie vorher berechnet hat. Er handelt da aber keineswegs bewußt, geschweige denn überlegen: Zwar weiß er plötzlich, daß es der falsche Schlüssel ist, doch ist er von dieser Entdeckung so verwirrt, daß er es Kattwald sagt, als er ihm den Schlüssel aushändigt. Wenn der Alte ihm nicht glaubt, weil er die Wahrheit für eine Lüge hält, dann ist das auf besondere Weise komisch, weil Leon hier zum ersten Mal nicht die Wahrheit zum Zweck der Lüge eingesetzt hat. Opfer der Situationskomik ist deshalb nicht nur Kattwald, der in der Freude über den zurückgewonnenen Schlüssel den an dieser Stelle eher tragischen Helden Leon für einen lustigen Burschen erklärt, dem man nicht gram sein könne. Leon, gerade noch davongekommen,

Verbindungsfäden mehr auf zu der Tradition des Wiener Volkstheaters [...] Ein Märchenspiel ist es allerdings". Für Herbert Seidler (Studien zu Grillparzer und Stifter. Wien, Köln, Graz 1970, S. 67) hatte Weh dem, der lügt! dagegen noch fraglos "seine künstlerischen und motivlichen Wurzeln im Wiener Volksstück." Rolf Geißler (wie Anm. 19, S. 71) spricht von einem "märchenhaften Legendenspiel", mit dem Grillparzer "an das Alt-Wiener-Volksstück angeknüpft" habe. 
zeigt sich nicht im geringsten fröhlich-glücklich, sondern enttäuscht, weil nun nicht nur dem Kattwald, sondern auch ihm selbst der rechte Schlüssel abhanden gekommen ist. Er fühlt sich als Versager und ist damit reif, zwar noch nicht im Wortlaut an ein Wunder, wohl aber an die sichtbare Hilfe des Himmels zu glauben, als er plötzlich im Tor den von Edrita heimlich ins Schloß gesteckten Schlüssel entdeckt:

So will der Himmel sichtbar seine Wege?

Stehn Engel um uns her, die uns beschirmen? (V, 1130-31)

Edrita aber erklärt ihm, daß es nicht der Himmel gewesen sein könne, der ihm da geholfen hat, weil er doch, wie sie ihm vorrechnet, ein gewohnheitsmäßiger Lügner sei, indem er die Wahrheit nur als Mittel der Täuschung einsetze. Sie allein sei es gewesen, die ihm den Schlüssel besorgt habe. Im Zusammenhang mit dem Vertrag, den Leon mit dem Bischof geschlossen hat, demonstriert die Opposition Himmel-Edrita natürlich die Versucherrolle Edritas gegenüber Leon.

Von nun an verzichtet er auf den bisher praktizierten Mißbrauch der Wahrheit, und zwar ausdrücklich entgegen den Plänen Edritas. Die nämlich betreibt zur Deckung der Flucht den rücksichtslosen Einsatz von List und Täuschung. Dabei hat sich Grillparzer, was ihren Beitrag zur Befreiungsaktion anlangt, hier weiter an das Schema des Märchens gehalten; der Held, der das Ungeheuer nur vorübergehend unschädlich machen konnte, muß von der schönen Prinzessin mit den nötigen Zauberworten und Weginstruktionen versehen werden, die ihm helfen sollen, mit seinem Beutestück den wütenden Nachstellungen des Drachen, des Riesen oder der Hexe zu entkommen. In diesem Sinne verrät Edrita Leon das Losungswort, das ihm den Weg durch die Wachen eröffnen soll, und empfiehlt ihm ausdrücklich das Mittel der Täuschung gegenüber dem Fährmann am Fluß, wobei sie ihn obendrein ironisch-spitzbübisch, im Sinne eines nicht ernst zu nehmenden Witzes, mit der Mahnung neckt: "wenns die Wahrheit dir erlaubt".

Eben aber, weil er sich von seiner Verpflichtung zur Wahrheit von nun an nicht mehr abbringen lassen will, fehlen dann im vierten Aufzug völlig die Märchenzüge, die den dritten kennzeichneten.

Der Grund liegt eindeutig in Leons Gesinnungswandel. Seit er weiß, daß er dem Ungeheuer nicht durch göttliche, sondern durch Edritas Hilfe entkam, möchte er mit dem dienstbaren Geist des Märchens nichts mehr zu tun haben und lehnt jede weitere Hilfe von ihr ab. Den ganzen vierten Aufzug hindurch liegt er mit ihr über den einzuschlagenden Weg im Streit. Sie allein ist aktiv, er nur reaktiv, und die für ihn schmerzhafte Komik besteht darin, daß er dazu verdammt ist mitzuerleben, wie sie die ganze Zeit genau die Mittel einsetzt, die er, nachdem er sie vorher so meisterlich eingesetzt hatte, nun nicht mehr akzeptieren kann. Dieselbe Edrita, die ihm im dritten Aufzug aus der Misere geholfen hatte, in die ihn seine 
Betrugsmanöver geführt hatten, beweist ihm nun, wie begrenzt sie als der "Engel" ist, den sie da für ihn ersetzen möchte. An ihrem Verhalten muß er erfahren, wie die Methode der Übertölpelung zugleich Ausdruck der Menschenverachtung gegenüber dem Betrogenen ist. Als sie den Verfolger Galomir mit schneller List zum Gefangenen gemacht hat, behandelt sie ihn mit überheblicher Roheit, indem sie ihm eine zukünftige Ehe vortäuscht, um ihn als ihren Gefangenen umso tiefer zu demütigen, ${ }^{22}$ und Atalus läßt sich von ihr anstecken, indem er sogar vorschlägt, den gefangenen Galomir lieber zu töten als gebunden zurückzulassen. Leon dagegen bewährt gegenüber dem hilflos-sprachlosen Barbaren Galomir eine ganz unerwartete, geradezu ritterliche Höflichkeit und ein besorgtes Mitgefühl.

Doch ist hier natürlich, abgesehen von Galomir, nicht nur Leon das tragikomische Opfer von Edritas fragwürdigem Lernfortschritt. Sie selbst, die doch nur praktizieren will, was sie von Leon gelernt hat, erntet damit bei ihm keinen Lohn und muß in der Folge auch aus anderen Gründen sehr bald die Grenzen ihres Witzes erfahren. Letzteres auf eine Weise, die wieder an den Schlußteil der Euripideischen Iphigenie erinnert. Wie es dort nämlich die Fliehenden mit ihrer List zwar bis zum Schiff gebracht haben und dann trotzdem noch von den Barbaren überwältigt zu werden drohen, so hätte um ein Haar auch hier die Flucht im Desaster enden können, wenn Edrita sich mit ihrer List gegenüber Leon durchgesetzt hätte. Sie, die sich wie der Geist des Märchens mit der Allmacht der Allwissenheit ausgestattet glaubt ("Da ihr nicht wußtet, was nur ich kann wissen", V, 1279) kann nicht verstehen, warum Leon, als sie beim Fluß angekommen sind, bei einem Heiligenbild niederkniet. Warum betet er, statt ihrem Rat zu folgen und sich beim Fährmann als Knecht Kattwalds auszugeben? Ihr, die bisher die Flucht so überlegen und erfolgreich organisiert hat, scheint sein Verhalten einfach unklug: "Wie unvorsichtig! Jetzt dorthin zu knien." (V, 1407) Doch hat sie unrecht. Nicht ihr Versuch, den Fährmann zu überlisten, sondern Leons Gebet bringt ihn dazu, die Fliehenden überzusetzen. Der Anblick des vor dem Heiligenbild knienden Leon hat ihn überzeugt, daß er es mit einem jener Franken zu tun hat, denen zu dienen sich mehr auszahlt als dem barbarischen Grafen Kattwald - eine Einschätzung, in der ihn Leon bestätigt, indem er sich nicht nur offen als Franke bekennt, sondern sogleich bereit ist, für die Überfahrt

22 Angesichts dieser Szene fragt man sich, wie Delphendahl (op. cit., S. 93) erklären kann: "Edrita hat die Eigenschaften eines sittlich entwickelten Menschen. [...] Edritas Wahrhaftigkeit ist ein ganz natürlicher Teil ihres Wesens. Als Naturkind entfaltet sie sich unbewusst und instinktiv. Als naturnaher Mensch ist sie ohne Verstellung und spricht unverfälscht [...]". Genauso fragwürdig scheint es, wenn Rolf Geißler (wie Anm.19), S. 80 Edrita zur Leitfigur des Lustspiels erhebt, mit deren Hilfe er das Ende des Lustspiels wie folgt interpretiert: "Die Humanität, wie sie Edrita während der Befreiungshandlung praktiziert hat, bleibt eine Aufgabe, könnte der Weizen sein [...]". 
zu zahlen. ${ }^{23}$ Wäre es dagegen nach Edrita gegangen, so wäre ihre List auf die Gegenlist des Fährmanns getroffen, der bereits geplant hatte, die Flüchtlinge auf dem Schiff von seinen Leuten überfallen zu lassen. Und noch eine zweite List Edritas erweist sich hier als ohnmächtig. Zwar hatte sie ohne größere Anstrengungen einen Teil der Verfolger in die falsche Richtung locken können, weiß aber nicht, daß der andere Teil sich nicht hat ablenken lassen und ihnen nun, während sie auf dem Fluß sind, an einer engen Stelle auflauert. Daß die Fliehenden es mit großer Anstrengung ("sie staun mit Macht den Strom," V, 1558) dann doch schaffen, die Mitte des Stromes zu halten, und also für Kattwald und seine Leute nicht erreichbar sind, ist nicht nur der Anstrengung der Ruderer zu verdanken, sondern auch der Strömung, die sich im Lustspiel, anders als in der Tragödie des Euripides, bezwingen läßt und kein wunderbares Eingreifen des Himmels mehr nötig zu machen scheint.

In dem Monolog, mit dem Leon den fünften Aufzug eröffnet, ist sein Blick jedoch schon wieder auf die bedrohliche Zukunft gerichtet.

Wie bedrängend ist seine Lage wirklich? Richtig ist, daß sie sich auch nach der Flußüberquerung weiter in einem von den Barbaren beherrschten Gebiet befinden. Außerdem hat Kattwald am Ende des vierten Aufzugs vom Ufer aus erneut blutige Rache geschworen im Vertrauen darauf, daß Galomir die Fliehenden mit Hilfe einer Furt im Fluß schon noch erreichen werde. Die Befreiungsaktion ist also in der Tat noch nicht endgültig durchgestanden. Trotzdem steht das Ausmaß von Leons Sorge offenbar in keinem Verhältnis zum Anlaß, scheint vielmehr paradox übertrieben. Je näher er seit dem vierten Aufzug wieder an sein Heimatland herangekommen ist und je mehr er sich damit der erfolgreichen Beendigung seiner Aufgabe nähert, desto weiter glaubt er sich von der Lösung entfernt. Beziehungsweise einer Lösung nahe, die seinen Opfertod verlangt. Während Edrita und Atalus schlafen, wacht er voll Sorgen über die beiden "wie die Mutter" über ihre Kinder $(V, 1570)$, und ist diese Metapher schon komisch genug, so steigert er sich dabei in der Erwartung seiner nächsten und letzten großen Prüfung sogar bis in die Rolle Jesu am Ölberg:

Sie sind ermüdet bis zum bleichen Tod.

Trag du allein, Leon, trag du für alle. (V, 1585-86)

23 Nach der richtigen Beobachtung von Delphendahl (wie Anm. 17, S. 94) ist es hier "die Wahrhaftigkeit Leons, die den Fliehenden das Leben rettet," auch wenn der Fährmann weniger an der Wahrhaftigkeit als an dem sie qualifizierenden Geld interessiert ist. 
Da er das Gefühl hat, wie Jesus die Last für alle tragen zu müssen, empfindet er seine Müdigkeit wie die Erschöpfung bis in den Tod, die Jesus empfand, als er allein wachen mußte, während seine Jünger schliefen. Dabei projiziert er jedoch seine eigene Müdigkeit und Todessehnsucht auf Atalus und Edrita, die ihrerseits, eben weil sie schlafen können, keineswegs an tödlicher Erschöpfung leiden. ${ }^{24}$ Und wie Jesus von Judas verraten worden war, so ruft Leon: "Verrat!", als er plötzlich wirklich von Galomir und Knechten Kattwalds überfallen wird. Doch verraten von wem? Sicher nicht von Galomir und seinen Leuten, die ihm mit Recht, da er Atalus entführt hat, den "Verräter" zurückgeben. Für Leon freilich stellt sich diese Frage nicht. Vielmehr begehrt er sogleich, für seine beiden Begleiter zu sterben. Das wirkt wiederum umso verquerer, weil die Opfergeste ja an die barbarischen Verfolger gerichtet ist, die anders als der Gott der Christen an einem stellvertretenden Opfer nicht interessiert sind. Schließlich haben sie, als erstes auf ihn selbst gestoßen, doch sogleich nach den beiden anderen gesucht. Und außerdem ist Galomir ja keineswegs auf Edritas Blut aus, sondern er will sie zur Frau, ein Begehren, für das das Blut Leons als absurdes Tauschobjekt erscheint.

Erst in dieser aussichtslosen Lage findet Leon nun doch wieder - wie im vierten Aufzug auf der anderen Seite des Flusses - zum Gebet. Zuerst versucht er, Gott gleichsam mit guten Worten zu der Einsicht zu bringen, daß es nicht recht sein könne, wenn Atalus zu den Barbaren zurück müsse. Sei es doch abzusehen, daß der verweichlichte Neffe des Bischofs dann verzweifeln und von Gott abfallen müsse, was wiederum Unrecht am Bischof wäre, der vor Kummer sterben werde. Da er aber immer noch keine rettende Antwort bekommt, wechselt er von der dringlichen Mahnung zur Forderung:

Wohlan, so gilt es denn das Letzte?

Ich bitte nicht mehr Hilfe, nein, ich fordre. (V, 1681-82)

Er fordert, weil er nach seiner Gottes-Erscheinung im ersten Aufzug - und nach der zugehörigen Deutung durch den Bischof - glaubt, einen Anspruch auf Gottes Hilfe zu haben. Und diesen Anspruch macht er nunmehr explizit:

Und so begehr ich denn, ich fordre Wunder!

Halt mir dein heilig Wort! - Weh dem, der lügt! (V, 1687-88, Hervorhebung H.D.)

24 Dieser Unterschied zwischen Leon und den beiden Schlafenden bezeichnet zugleich den Unterschied zwischen Leon und den beiden Freunden Orest und Pylades in der Tragödie die Euripides. Dort sind beide bereit, für einander zu sterben, leiden dabei aber keineswegs an jener Erschöpfung zum Tode, die Leon mit dem Goetheschen Orest gemein hat. Bei Euripides sagt Orest über Pylades, dem er mit seinem eigenen Tod das Leben retten will: "Dieser ist mein edler Freund / Und wie mir selber, wünsch ich ihm der Sonne Licht." (Euripides, Sämtliche Tragödien. Nach der Ubersetzung von J.J. Donner. 2. Bd. Stuttgart 1958, S. 151.) 
Natürlich wirkt das nach dem Vorigen wie eine komische Umkehrung des Jesuswortes: "Doch nicht, wie ich will, sondern wie du willst." In dem überspannten Anspruch, sich sogar gegen Gott durchsetzen zu müssen und zu können, scheint Leons Rede plötzlich die abgrundtiefe Melancholie zu überwinden, die ihr vorausgegangen war. Und wirklich wird er nach dem aus der Bedrängnis verständlichen, aber trotzdem unübersehbar anmaßenden Gebet von Gott nicht etwa auf seine Grenzen verwiesen und für seine Anmaßung bestraft. Gott scheint vielmehr auf die fordernde Mahnung einzugehen, sich sozusagen von dem Betenden zur Ordnung rufen zu lassen; denn das Wunder geschieht: Die Besatzung der Stadt besteht plötzlich aus Christen, die Gefangenen sind frei, und Galomir und seine Leute sind die Gefangenen. Leon ist überwältigt vor Freude über das erfolgreich herbeigezwungene Wunder, wie aus der Regieanweisung abzulesen ist, nach der er sich an Edrita wendet, "ihr Gesicht zwischen beide Hände fassend": "Edrita, schau! Da sind wir bei den Unsern." (V, 1703) Mit seinen Worten lenkt er da ihren Blick auf "die Unseren", mit seiner Geste aber auf sich selbst. Das Wunder hat ihn alle seine selbstquälerischen Bedenken, mit denen er bisher auf seine Liebe zu Edrita aus Gewissensgründen verzichten wollte, vergessen lassen. Seine Freude über die Rückkehr zu den Seinigen erfüllt sich erst in der Freude, Edrita nunmèr zu den Seinigen rechnen zu können, da sie es doch ist, die ihm mittlerweile für sein eigentliches Zuhause steht, nicht die, zu denen er zurückgekehrt ist.

Grillparzer hat hier offenbar das Motiv des Wunders, das Goethe in seiner Iphigenie auf Tauris in eine neuzeitliche Glaubensform transponiert hatte, mit Hilfe der mittelalterlichen Gläubigkeit Leons wieder mehr an die altertümliche Euripideische Form der Wundererscheinung angeglichen. Allerdings hat er dabei das Wundermotiv der Tragödie dadurch ins Komische verkehrt, daß er aus der objektiven Wunderscheinung, die das Eingreifen der Götter bei Euripides darstellt, in seinem Lustspiel eine subjektive Erscheinung machte, die der Zuschauer als Fehlinterpretation objektiver, auch ohne Wunderglauben leicht erklärbare Fakten durchschauen konnte. In diesem Punkt blieb er also doch wieder mehr bei Goethe, da schon das von Iphigenie von den Göttern erbetene Wunder, die erfolgreiche Überredung des Thoas mit den Mitteln der Wahrheit, längst vor ihrem Gebet als Möglichkeit in ihr (und Thoas) bereit lag, auch wenn sie diese Möglichkeit erst in einem bestimmten Moment des Stückes als solche wahrnimmt.

In Wahrheit sind aber mit dem scheinbaren Wunder von Metz die Probleme Leons noch keineswegs gelöst. Das hat ausdrücklich nichts damit zu tun, daß eine übernatürliche Verwandlung von Ungläubigen in Christen in Wahrheit gar nicht stattgefunden hat, da die Christen schon in der Stadt waren, bevor er von Gott das Wunder forderte, ${ }^{25}$ es des Wunders, das nur in seinem Kopf stattfand, 
also gar nicht bedurfte. Keine Rede davon, daß hier oder später Leons Wunderglaube von ihm oder irgendeiner anderen Figur des Lustspiels als bloßer Aberglaube entlarvt würde. Es stimmt zwar: Die vorige Behauptung der Verfolger, es handele sich bei der Besatzung von Metz um Ungläubige, war nichts als ein Irrtum, eine bloße Fehlinformation gewesen. Doch seine äußeren Umstände haben sich tatsächlich zum Positiven verändert. Komischerweise ist es aber gerade diese Wendung zum Positiven, mit der er seine Schwierigkeiten hat. Problematisch wird ihm also nicht die Scheinhaftigkeit des Wunders, sondern im Gegenteil dessen für ihn unbezweifelbare Faktizität. Edrita, deren Gesicht er zwischen seine Hände genommen hat, wird ihm plötzlich in einem einzigen, komisch ernüchternden Augenblick von der Verkörperung seines Glücks zur Verkörperung seiner Schuld:

Ja so, du bist im Ganzen doch der dunkle Fleck. (V, 1704)

Um welche Schuld handelt es sich? Die Antwort, die er sich selbst schon vorher mehrfach darauf zu geben versuchte, blieb stets an der Oberfläche. Jedesmal wollte er sich da eine Schuld einreden, die er nicht hatte. Zwar hat er in seiner Beziehung zu ihr gegen das Wahrheitsgebot verstoßen, doch gerade nicht, indem er sie ihrem Vater raubte, sondern indem er umgekehrt das Versprechen, das in seiner Zuneigung zu ihr lag'6 ${ }^{26}$ ihr gegenüber nicht wahrhaben und nicht wahrmachen wollte. ${ }^{27} \mathrm{Zu}$ Beginn des fünften Aufzugs (V, 1593) fällt ihm im übrigen selbst auf, daß er sich im Wort vergriffen hat, als er sich beschuldigt, sie ihrem Vater geraubt zu haben. Er hatte ihr ja nur "gestattet", daß sie ihm folge, und sogar das war eigentlich eine falsche Selbstbezichtigung gewesen, weil er sie ja in Wahrheit durch sein stetes "Weigern" und "ernstes Mahnen" immer wieder von sich fort zu Atalus getrieben hatte. ( $\mathrm{V}, 1604 / 5)$

Warum also beharrt er darauf, daß er sich mit ihr schuldig gemacht habe? Warum beharrt er nur auf dem Schuldhaften des Versuchs, sie zu rauben, während er im dritten Aufzug seinen Schlüsselraub ohne Bedenken damit rechtfertigte, daß er ihn doch nur einem "Raubtier" rauben wollte? ${ }^{28}$ Eine näherliegende, von Leon nicht ins Bewußtsein gehobene Erklärung betrifft Vertrag und Wette vom ersten

gesprochen wurde, vgl. auch Iphigenie auf Tauris V. 1102-04, und zum Motiv des Gebets, das erfüllt wird, bevor es dem Betenden zuzustehen scheint, V. 1604-06.)

Am Ende des zweiten Aufzugs, als sie Hand in Hand zusammen fortlaufen und auch Kattwald diese Vertrautheit als eine Bedrohung für Galomirs Ansprüche an Edrita versteht.

27 Darauf versucht ihn Edrita in V, 1798 aufmerksam zu machen.

28 Das einzige, woran ihn sein Gewissen bei der Gelegenheit erinnerte, war, daß es ihm verboten wäre, sich mit Lügenkniffen herauszureden, sollte Kattwald aufwachen. 
Aufzug. Er hat Angst, durch seine Liebe zu Edrita gegen den Vertrag zu verstoßen, indem er sich von ihr zu seinem Glück sozusagen an Gott vorbei verhelfen läßt, will sagen: ohne Erfüllung jenes Vertrags, den er durch die Vermittlung des Bischofs mit Gott geschlossen hatte. Die erste Versuchung ergab sich, als Leon und Edrita am Ende des zweiten Aufzugs Hand in Hand davonliefen, die zweite, als sie sich ihm im dritten Aufzug versprach, wenn er bei ihrem Vater bleiben wolle, die dritte, als er im fünften Aufzug ihr Gesicht in beide Hände genommen und sein kompliziertes Verhältnis zu Gott für eine Sekunde vergessen hatte. Alle diese Versuchungen hat er nach außen hin erfolgreich bestanden, aus seiner Seele aber kann er sich seine Liebe zu Edrita nicht herausreißen. Da er unbedingt an dem Vertrag festhalten möchte, will er seine Liebe nicht wahrhaben und also versucht er vergeblich, seinem Schuldgefühl mit der These des Frauenraubs einen anderen Inhalt zu geben. Befreiung von seinem Schuldbewußtsein oder von seinem Gefühl, versagt zu haben, und Erlaubnis zur Wahrnehmung seines Glücks kann ihm demnach nur von Gott selbst gewährt werden - oder von seinem Stellvertreter, Gregor, der an dieser Stelle des Lustspiels wieder auf die Bühne tritt und dank der Autorität seiner Person und seines Amtes sogleich wieder zum Zentrum der äußeren Handlung wird.

So, wie wir den Bischof aus dem ersten Aufzug in Erinnerung haben, stehen die Chancen für Leon da zunächst keineswegs gut. Die Verse, mit denen der Bischof hier zum ersten Mal wieder das Wort an ihn richtet, zeigen denn auch, daß der sein Lügenverbot nicht vergessen hat. Seine Worte sind freilich durch einen Gedankenstrich in zwei Hälften geteilt, deren erste durchaus noch ungeteilte, weil unreflektierte Freude erkennen läßt, eine Freude, in der sich Dankbarkeit für das überraschende Gelingen der Befreiungsaktion ausdrückt. Für einen Moment vergißt er sogar seine bischöfliche Würde:

Ha, du mein toller Bursch. Mein Wackrer, Treuer!

Hier meine Hand! Nicht küssen, drücken -...(V, 1716/17)

Nach dem Gedankenstrich aber ruft er sich zur Besinnung mit einem gedehnten "So", das wie ein Echo auf das "Ja so" wirkt, mit dem Leon von seiner Freude über den Anblick Edritas zu der enttäuschten Feststellung übergeleitet hatte, daß sie "im Ganzen doch der dunkle Fleck" sei. Entsprechend anzüglich fährt der Bischof nach dem Gedankenstrich (und jenem "So") fort:

$\mathrm{Nu}$, hübsch gelogen? Brav dich was vermessen?

Dem Feinde vorgespiegelt dies und das?

Mit Lug und Trug verkehrt? Ei ja, ich weiß. (V, 1718-20)

Das ist von oben herab gesprochen, hat er doch, wie ihm seit dem ersten 
Aufzug längst bewußt geworden ist, von vornherein mit dem Versagen Leons rechnen müssen. Gleichzeitig aber zeigt es, daß er seine vorige Einstellung zur Wahrheitsfrage mittlerweile geändert hat. Deutlich mag er der Lüge nicht mehr dieselbe absolute Bedeutung zuerkennen wie damals, will Genaueres nicht wissen und es lieber mit diesen rhetorischen Fragen bewenden lassen. Leon jedoch mag, was seine Neigung zur Lüge anlangt, den Vorwurf nicht unkommentiert auf sich sitzen lassen. Zwar will er sein Versagen in diesem Punkt weder leugnen noch entschuldigen, wohl aber darauf hinweisen, daß es an seinem guten Willen nicht gefehlt hat:

$\mathrm{Nu}$, gar so rein gings freilich denn nicht ab.

Wir haben uns gehütet, wie wir konnten.

Wahr stets und ganz war nur der Helfer: Gott! (V, 1721-23)

Geflissentlich überhört der Bischof die in diesen Worten indirekt geäußerte Kritik an dem Absolutheitscharakter seines früheren Wahrheitsgebots. Dafür bringt er es fertig, indem er zunächst nur auf den letzten Teil von Leons Worten eingeht, dessen Aussage gleichzeitig zuzustimmen und sie durch weitere Verstärkung zu korrigieren - und auf diese Weise im Lobpreis Gottes am eigenen Absolutheitsanspruch festzuhalten:

\section{Das ist er auch in allen seinen Wegen! (V, 1724)}

$\mathrm{Da}$ er auf diese Weise an seinem Absolutheitsgebot festhalten will, ist Ausdruck einer menschlichen Schwäche, nämlich seines Stolzes. Der war uns an bedeutsamer Stelle schon früher begegnet, und auch da in Verbindung mit seinem Absolutheitsdenken. Sein Stolz war es gewesen, der ihn gegenüber dem König hatte behaupten lassen, daß er keinerlei Hilfe benötige. $\mathrm{Zu}$ Beginn des Stückes war er sich dieses Stolzes denn auch als eines Lasters bewußt (V. 159), das er mit der strikteren, ja absolut strikten Anwendung des Lügenverbots überwinden wollte. Indem er aber die Last der Ausführung Leon zuschob, konnte ihm die auf neue Weise versuchte Befreiung des Neffen in Wahrheit auch gerade umgekehrt dazu dienen, seinen gedemütigten Stolz zurückgewinnen. Und da er Leon eine Aufgabe zuwies, mit der er ihn von Anfang an hätte überfordert wissen müssen, weil ihm sein unzähmbarer Hang zur Lüge bekannt war, war sein Stolz nicht nur für seine Unwahrheit gegenüber dem König, sondern indirekt auch für Leons Verstöße gegen das Lügenverbot verantwortlich.

Durchaus verständlich also, daß er sich nun über seine Verlegenheit mit der Bitte um die Freilassung Galomirs und seiner Leute hinwegzuhelfen sucht, diese Bitte mit einem "Und so" einleitend, das einen einfachen logischen Zusammenhang suggeriert, wo es sich um eine durchaus eigenwillige Folgerung handelt: 
Und so in seinem Namen bitt' ich Euch,

Laßt los die Männer hier, gönnt ihnen Heimkehr. (V, 1725-26)

Offenbar ist der Gedankengang des Bischofs wie folgt: Zwar ist, wie Leon richtig erinnert hat, die Wahrheit im Detail wirklich nur Gott selbst bekannt, doch ist es dem Bischof gegeben, sie im "Ganzen"29 zu definieren. Die dabei praktizierte Neudefinition der Wahrheit als fortschreitende Annäherung an menschliche Freiheit, die durch den Verzicht auf Zwang gegenüber dem Mitmenschen erreichbar ist, hat den Vorteil, daß sie bei oberflächlichem Hinsehen nichts als die Kontinuität seiner Zwecke unterstreicht. Um die Freiheit des Atalus war es ihm ja schon im ersten Aufzug zu tun, und da diese Freiheit mittlerweile erreicht wurde, ist die Bitte um Freilassung Galomirs gleichzeitig so etwas wie eine Geste der Dankbarkeit gegenüber Gott, der sich gerade erst so sichtbar "in allen seinen Wegen" als wahr erwiesen hat.

Die gewählte neue Definition ermöglicht es ihm aber auch, gleich darauf erneut "stark", also im Absolutheitston unerbittlicher Autorität zu sprechen, sowie er auf die Anwesenheit Edritas aufmerksam wird: "Tatst du mir das!" Weil Edrita Leon gegen seinen Willen gefolgt ist, besteht die Komik darin, daß der Bischof, statt von Leon getäuscht worden zu sein, sich hier in Wahrheit selbst in seiner Deutung der Fakten täuscht. Obendrein aber hat er da offenbar das frühere Lügenverbot mit dem gerade erst in den Vordergrund gerückten Zwangsverbot vertauscht, von dem in seinem Befreiungsauftrag an Leon noch gar keine Rede gewesen war. So verknüpft er die neue Definition der Wahrheit mit der alten auf eine Weise, die den Druck auf Leon nicht mindert, sondern erneuert.

Weil aber Leon im Hinblick auf Edrita seine Schuld von sich aus, wenn auch aus anderen Gründen als der Bischof (siehe oben), für nicht entschuldbar hält, kann er an dieser Stelle nichts anderes vorbringen als die Bitte um Verzeihung. Anders verhält es sich mit Edrita und Atalus. Mit Recht hatte Edrita darauf verzichtet, sich vor dem zu "reinen", der sie als "dunklen Fleck im Ganzen" bezeichnet hatte. Dafür hilft sie ihm nun, indem sie ihn von ihrer Flucht aus dem Vaterhaus gegenüber dem Bischof gleich doppelt entlastet: durch das Bekenntnis ihrer Liebe, mit dem sie die Hauptschuld an ihrer Flucht auf sich nimmt, und durch ihr Verlangen nach christlicher Bekehrung, mit dem sie das gerade erst formulierte Zwangsverbot des Bischofs aufweicht. Zwar will sie nicht leugnen, daß sie ihren Vater gegen seinen Willen verlassen hat und daß ihm insofem tatsächlich Zwang angetan wurde, doch kann sie den Bischof, ohne daß er es merkt, mit der Folgerung bestechen, daß sie auf diese Weise auch ihrem Vater den Weg zu christlicher Bekehrung geöffnet hat. Wird doch auch der Vater, wenn er seine Tochter zurückholen will, in den Einflußbereich der missionarischen Franken geraten.

29 Das war die Formel, die Leon V, 1704 gegenüber Edrita gebraucht hatte. 
Als Edrita sich auf diese Weise gegenüber Gregor so weit "gereint" hat, daß er sogar bereit ist, sie mit seinem Neffen zu verheiraten, wird Leon eifersüchtig. Obwohl gerade noch der Angeklagte, war er dem Bischof über der Rechtfertigung Edritas völlig aus den Augen geraten, weil er auf seine Verteidigung verzichtet hatte. Jetzt aber hat er seine Sprache wiedergefunden. Weil er nicht miterleben möchte, daß Edrita die Frau des Atalus wird, will er den Dienst des Bischofs quittieren. Der jedoch ahnt, daß Leons Begehr nicht, wie von ihm vorgeschützt, einer allgemeinen Reiselust, sondern seiner Enttäuschung und Unzufriedenheit zu verdanken ist, und besteht ("Weh dem, der lügt!") auf Leons Bekenntnis seiner Liebe. Da Atalus ebenso großherzig wie realistisch auf Edrita verzichtet, weil sie nicht ihn, sondern Leon liebt, scheint Gregors Zustimmung zur Verbindung Leons und Edritas am Ende nichts mehr entgegenzustehen.

Und doch noch kein Vorhang. Statt dessen rückt das Schicksal Leons und Edritas zunächst noch einmal an die Peripherie. Es ist Atalus, der, als der im Wettbewerb um Edritas Liebe Unterlegene, noch Anspruch auf des Bischofs Mitgefühl und Trost hat, so wie natürlich der Bischof, was den Ausgang jener unausgesprochenen Wette vom Anfang des Stücks anlangt, auch selbst des Trostes bedarf. Schließlich hatte er gegenüber Leon darauf gesetzt, daß wahres Glück nur durch den Verzicht auf die Lüge zu erreichen sei. Die Niederlage des Atalus, der über jeden Verdacht der Lüge jederzeit erhaben war, muß ihm nun das Glück Leons moralisch umso fragwürdiger erscheinen lassen. Doppelt verständlich also, daß er das Glück Leons und Edritas relativieren möchte, indem er die zerstörte Liebeshoffnung des Neffen als das in Wahrheit größere Glück hinstellt. In seiner Schlußansprache lenkt er den Blick auf das absolute Glück der ewigen Seligkeit, auf das Atalus sich von nun an konzentrieren wird, und bringt es damit fertig, seine Absolutheitshaltung, die für ihn zû seiner Rolle als Stellvertreter Gottes gehört, noch einmal fulminant zu steigern.

Der Neffe möge, so der Rat des Bischofs, das "Aug vom Boden" heben, um jenes "andere Land" in den Blick zu nehmen, das ihm wahres Glück verspreche. $(V, 1815 / 16)$ Der dem Atalus empfohlene Blick nach oben erinnert dabei an das Verfahren, mit dem Goethe zu Beginn des Zweiten Teils seinen Helden in die Wirklichkeit zurückfinden läßt. Es ist die Stelle, an der Faust lernen muß, ohne Gretchen zu leben und also für sein Leben neue Orientierung zu finden. Er wendet da seinen Blick, als er von seinem Heilschlaf aufgewacht ist, der aufgehenden Sonne zu, die an dieser Stelle natürlich ebenso Symbol Gottes wie der Wahrheit ist. Schnell sieht er ein,"vom Augenschmerz durchdrungen", daß er den Blick wieder von der Sonne fort zur Erde wenden muB, wo er ihn im wohltätigem "Schleier" des bunten Regenbogens "bergen" kann. (Faust, V. 4702-14) Der 
Blick nach oben zwingt ihn also in seinem Bemühen um die Wahrheit zur Selbstbescheidung. Die aber ist, wie wir längst wissen, nicht nur von Atalus, sondern auch vom Bischof selbst gefordert, ja, sie bezeichnet dessen ureigenes Problem. Man braucht es nicht noch einmal zu rekapitulieren, daß es vom Stolz diktierte Täuschung und Selbsttäuschung gewesen waren, deretwegen er dem König erklärt hatte, daß er seiner Hilfe nicht bedürfe, und daß diese Täuschung sich wiederholt hatte, als er glaubte, die Befreiung des Atalus durch die Befolgung des absolut gesetzten Lügenverbots erreichen zu können. In seiner Schlußansprache wiederholt sich die Selbsttäuschung nun ein drittes Mal, und wieder ist sie die Folge des Versuchs der Selbstbescheidung, der in Selbstüberhebung umschlägt. Er wechselt nämlich von dem Wort "Täuschung", das für Atalus' falsche Einschätzung seiner Beziehung zu Edrita oder auch für seine eigene Einschätzung der Rolle der Lüge angemessen war, zwei Verse weiter zu dem Wort "Lüge", also zu dem Begriff des bewußten Verstoßes gegen die Wahrheit, auf den er sich zu Beginn des Stücks gegenüber Leon als auf das Prinzip des Bösen schlechthin festgelegt hatte. Nur dadurch, daß er sich in die Position Gottes versetzt, gewinnt er die Ganzheitsperspektive, die es ihm erlaubt, in der Lüge nunmehr nicht mehr wie zuvor das schlechthinige Prinzip des Bösen zu sehen. Wie er die Bedeutung der Lüge zuvor in grotesker Verabsolutierung überschätzt hatte, so verharmlost er sie nun, indem er in ihr "nur ein buntes Kleid" sieht, das zur Schöpfung gehört, sofern sie vergänglich ist $(\mathrm{V}, 1818-19)$, und das für die Menschen erdacht wurde, damit "ihre Augen nicht am Strahl [sc. der Wahrheit] erblinden." (V, 1821) ${ }^{30}$

Das von Gregor propagierte "andere Land", das Land "aller Wahrheit", ist also in seiner Predigt nicht etwa nur ein unerreichbar fernes Jenseits. Es umfaßt zugleich das unvollkommene Diesseits - in einer Beleuchtung, die nur, wenn man es nicht so genau nimmt, dessen Unvollkommenheit vergessen läßt. Der Bischof freilich vergißt sie nicht, und seine gewagte Entschuldigung der Lüge mit den höheren Zwecken der Wahrheit bedeutet keineswegs, daß er sich mit den Unzulänglichkeiten der Wirklichkeit nun abgefunden hätte. Vielmehr will er diese Unzulänglichkeiten hinter sich lassen, und also gerät er von hier an mehr und mehr in den Redeschwung des Predigers, der den einzelnen Adressaten vergißt, weil er gewohnt ist, seine Worte an eine Gemeinde, ja, an die Menschheit zu rich-

30 Die Redewendung vom "bunten Kleid" dürfte auf die erste Szene des Ersten Teils des Faust zurückgreifen, wo das Tun und Wesen des Erdgeists, sein "wechselnd Weben", darauf gerichtet ist, "am sausenden Webstuhl der Zeit" "der Gottheit lebendiges Kleid" zu weben. Offenbar hat Grillparzer diesen Ausdruck nicht als Kleid zum Schmucke Gottes gedeutet, sondern als ein Kleid, das von Gott zur Bekleidung und zum Schutz der Menschen erdacht ist. Die Menschen bedürfen seiner, weil ihr Leben durch Wechsel und Vergänglichkeit definiert ist; direkte und ungeschützte (unverschleierte) Berührung mit der Wahrheit müßte das Ende des Wechsels und damit Tod bedeuten. 
ten, da sie insgesamt der missionarischen Botschaft seiner Predigt bedürftig ist. Entsprechend steigert sich nicht nur der Absolutheitston seiner Rede, sondern weitet sich der Raum, in dem sie sich bewegt, vom Diesseits zum Jenseits, die Zeit vom Jetzt bis zum Ende der Zeiten ("bis zu den spätsten Tagen") - und das Lustspiel zum Welttheater. Gregor wird hier ebenso zum Visionär ${ }^{31}$, wie am Ende jenes anderen Welttheaters Faust der Pater Seraphicus, der den ungeborenen Knaben seine eigenen Augen leiht, damit sie "zu höherm Kreise" hinansteigen und wachsen können, genährt durch die Offenbarung Ewigen Liebens, als die sich Gottes Gegenwart für sie erfüllt.

Doch dann spricht Gregor den letzten Vers des Lustspiels, sein Schlußwort an Leon und Edrita: "Und diese da, / Sie mögen sich vertragen." Das zeichnet sich aus durch schnelle Beiläufigkeit, ist gleichsam nur als Nachsatz geäußert und stiehlt doch der hier plötzlich verpufften Ekstase seiner so weit ausholenden Predigt die Schau. Offenbar muß er sich, um sein Postskriptum sprechen zu können, von den Höhen seiner visionären Schau in die Niederungen der Wirklichkeit zurückbegeben, und das fällt ihm nicht leicht. Als sich die beiden Liebenden in die Arme stürzen, wendet er sich sogleich zum Gehen, denn ihre Wirklichkeit ist nicht die seine. Für Leon und Edrita aber unterstellt er mit diesem abschlieBenden Vers, was auch für ihn selbst nicht wahr ist, daß nämlich die Erfüllung der Forderung, zusammenzubleiben und sich zu vertragen, leicht und wie nebenbei zu erreichen sei, wenn man sich nur darum bemühe. In seinem Schlußvers wiederholt er mithin die ebenso gut gemeinte wie anmaßende Haltung, mit der er Leon am Anfang zur Wahrhaftigkeit verpflichtet hatte. Und er spiegelt damit zugleich die Geradheit und Offenheit des Atalus, die diesen in den Augen Edritas wie ihres Vaters immer wieder zum verächtlichen Dummkopf gestempelt hatte - Wahrheitsliebe nicht als moralische Leistung, sondern als penetrante Selbstgerechtigkeit, mochte sie auch noch so sehr seinem adeligen Willen zu moralischem Verhalten zu verdanken sein. Wie diese Haltung dem Atalus bisher nicht zum Vorteil, sondern zum Schaden gereicht hatte, so wird auch der Bischof mit seinem Schlußwort in all seiner Erhabenheit wieder zur komischen Figur.

Da Gregor den Blick der Zuschauer aber am Ende von sich fort auf die beiden

31 An dieser Stelle bietet der Bischof das Bild des mystischen Visionärs, als den ihn Leon zu Beginn des Stücks schildert, um das Charismatische seines Äußeren zu verdeutlichen, das ihn dem Christentum gewonnen hat:

Die Augen aufgespannt, als säh er Bilder

Aus einem andern, unbekannten Land,

Die allzugroß für also kleine Rahmen [...] (V, 49-51)

Der Bischof findet also am Ende zurück zu einer Statur, die noch vor den Anfang des Stückes zurückreicht, also vor die Zeit seiner melancholischen Selbstzweifel, in die er wegen der aus Stolz zurückgewiesenen königlichen Hilfe bei der Befreiung des Atalus verfallen war. 
Liebenden gelenkt hat, darf nun abschließend von ihnen die Rede sein. In der Tat scheinen sie im Begriff, ihr Leben nicht auf eine visionäre Zukunft, sondern auf das Hier und Jetzt ihrer Liebe zu gründen. Davon, daß ihre Realität von der Gregors verschieden ist, bekommen sie nichts mit. Auf die gleich zu Anfang der Ansprache des Bischofs gegebene Erlaubnis, er dürfe das Häuptlingskind freien, hat Leon zunächst nicht reagiert, so wenig wie auf die ihm dabei versprochene Erhebung in den Adelsstand, die ihn, getreu den Versprechungen des lustspielhaften Märchenschemas, sozial auf dieselbe Stufe hebt wie Atalus. Zuletzt aber hat ihn der Redeschwung des Bischofs nun doch fortgerissen in sein Glück, wobei er aus der Aufforderung, sich zu vertragen, nur das eine heraushört: Er kann und darf eine neue Beziehung zu Edrita beginnen. Im Moment der Umarmung hat er völlig vergessen, daß er es war, der sich in der Befreiungsaktion im Gegensatz zu Atalus in seiner Beziehung zu Edrita mit Schuld beladen glaubte. Und Gleiches gilt für Edrita; auch sie glaubt sich am Ziel ihrer Wünsche. Für sie, die nie aus ihrem Land herausgekommen war, hatte das Land ihrer Sehnsucht genauso einen Namen wie für Iphigenie: das Land der Franken als das Land der Zivilisation und Kultur, der "frommen Lehren" "von Gott und Recht und Pflicht" (V, 1315-17). Ob sie aber am Ende mit dem Land der Franken das Land ihrer Sehnsucht erreicht hat, hängt davon $\mathrm{ab}$, ob Leon in $i h r$ sein Glück gefunden hat und von nun an Frieden halten kann. Sobald er neuen Streit ${ }^{32}$ mit ihr beginnt, wird das neu gewonnene Glück wieder ebenso gestört sein, wie es das seit Beginn des dritten Akts bis zum Ende des fünften bereits gewesen ist, bevor sie sich in die Arme fielen. Natürlich geht es dabei um weit mehr als den unvermeidlich bevorstehenden Abstieg vom Honeymoon in den Ehealltag. ${ }^{33}$ Von seinem religiösen Schuldbewußtsein, das ihn zuvor an einer harmonischen Verbindung mit Edrita gehindert hatte, hat ihn der Bischof mittlerweile kraft seines Amtes (und durch das ungewollte Schüren von Eifersucht auf Atalus) befreit. Doch lag Leons religiösem Schuldbewußtsein ja sein eigentliches Problem noch voraus, das wir schon zu Beginn als das Problem der Melancholie identifiziert hatten. Objektiv gesehen trägt deshalb der Bischof, indem er dem Bund der beiden Liebenden seinen Segen gibt, zu Leons Glück nicht mehr bei als zuvor mit seinem Einverständnis zu der

32 Nachdem sie ihre Zuneigung zu Leon im zweiten Aufzug ausdrücklich mit seiner Lustigkeit begründet hatte, war von einer solchen in den letzten drei Akten so gut wie nichts mehr zu spüren gewesen. Das bedeutete für ihn zwar eine Befreiung insofern, als er sich zu seiner Lustigkeit hatte zwingen müssen. Andererseits aber hatten sie seither, mit Ausnahme der Szene nach dem Wunder von Metz, fast nur im Streit gelegen.

33 Vgl. dazu auch die These von Sheila Jones, das Lustspiel sei in erster Linie "a statement about, or diagnosis of, a world torn apart by aggression." ("Weh dem, der lügt! Reconsidered in the light of some basic character types in Grillparzer's work", in: Bruce Thompson \& Mark Ward (eds), Essays on Grillparzer. New German Studies Monographs Vol. V. Hull 1978, S. 75). 
Befreiungsaktion im Rheingau oder mit seiner frommen äußeren Erscheinung, von der sich Leon überhaupt erst zu den Verheißungen der christlichen Religion hatte bekehren lassen. Am Ende scheinen alle die vielen Gründe für den glücklichen Ausgang des Lustspiels nicht stichhaltiger als das Scheinargument des Wunders von Metz zu Beginn des Aufzugs.

So endet das Lustspiel mit nichts anderem als einer bloßen Momentaufnahme des Glücks. Vor einem erneuten Ausbruch des Streits wird die beiden momentan Glücklichen weder die Revozierung des absoluten Lügenverbots von seiten des Bischofs bewahren, noch die progressive Gesellschaftspolitik, mit der er bereit ist, dem Küchenjungen zum Adelsprivileg zu verhelfen, ${ }^{34}$ noch auch Leons neu gewonnene Fähigkeit, oder doch Willigkeit, auf Lügen zu verzichten. In den Erkenntnisfortschritten, die Leon, der Bischof und Edrita machen, ${ }^{35}$ wenn man sie denn als Erkenntnisfortschritte ansehen möchte, eröffnet sich keine neue Menschheitsperspektive nach Art des Zukunftsoptimismus in Goethes Iphigenie. Durch nichts wird das so deutlich wie durch die unterschiedliche Verwendung des Wunder-Motivs. Der Erfolg von Goethes Heldin Iphigenie ist wunderbar im Sinne des Staunens- und Bewundernswerten; hat sie sich doch zu ihren Zwecken einer Methode bedient, die bis dahin für widersinnig gehalten wurde. Sofem ihr Erfolg jedoch der Erfolg ihrer Methode ist, nämlich der Entscheidung zu Wahrhaftigkeit und mutigem Gottvertrauen, ist er aus ihr erklärbar und verliert damit die Qualität des Wunders im Sinne des Euripides. In dessen Tragödie bezeugt das wunderbare Auftreten der Göttin nicht etwa die objektive Realisierung des Wunders, sondern gerade umgekehrt unser objektives Angewiesensein auf Wunder in einer Welt, in der sie sich nur auf dem Theater, nicht aber in Wirklichkeit ereignen. Von eben dieser Notwendigkeit und gleichzeitigen Unmöglichkeit von objektiven Wundern zeugt auch Weh dem, der lügt! Doch wăhrend Euripides das Wunder zum Nachweis der Unerreichbarkeit menschlichen Glücks einsetzt, zeigt uns das Lustspiel, daß wir - von Zeit zu Zeit - das Glück haben können, in den zwar flüchtigen und auf Selbsttäuschung beruhenden, ${ }^{36}$ aber dennoch realen Genuß des Wunders zu

34 Bernhard Budde ("Die List des frommen Knechts. Weh dem, der lügt!" In: Gerettete Ordnung. Grillparzers Dramen, hrsg. von B. Budde und U. Schmidt, Frankfurt/M.1987) möchte gegen Grillparzers eigene Zeugnisse die "klare antiaristokratische Tendenz" belegen, durch die das Stück ein bürgerliches Lustspiel werde. Das ist freilich nicht, wie der Leser zunächst glaubt, als Lob gemeint, vielmehr soll es die These stützen, daß sich das Stück als bürgerliches Lustspiel "um mindestens fünfzig Jahre verspätet hat." (S. 215)

35 Die "seelische Reifung der beiden Hauptgestalten" stellt Georg Scheibelreiter ("Franz Grillparzer und Bischof Gregor von Tours". In: Jahrbuch der GrillparzerGesellschaft. Dritte Folge. 15. Bd. (1983), S. 66) als Unterschied zwischen dem Lustspiel und Grillparzers historischer Quelle heraus.

Wenn man diese doppelte Einschränkung von Grillparzers Lustspielglück in den 
kommen. Eines Wunders, das darin besteht, unser Leben als erträglich, ja, als beglückend zu erfahren.

Grillparzers Lustspiel-Pendant zur Tragödie des Euripides bestătigt somit den Euripideischen Pessimismus aus einer Tiefenschicht der menschlichen Psyche, ${ }^{37}$ in der der Mensch ebenso radikal durch sich selbst bedroht scheint wie bei Euripides durch die äußere Welt. Eben diesen psychologischen Ansatz hatte Goethes Transformierung der Euripideischen Iphigenie-Tragödie in ein Drama der melancholischen Seele vorbereitet, um ihn doch sogleich wieder zu verkürzen. Zwar war der "dunkle Grund" auch in Goethes Iphigenie nicht nur Folie, wie es ein offenbar selbstironisches Goethe-Wort von 1815 für die Dichter überhaupt nahezulegen scheint; ${ }^{38}$ die Entdeckung der Gefährdung durch die eigene Seele war keineswegs etwas, das Grillparzer Goethe voraus hatte. Goethe hatte aber im Vergleich $\mathrm{zu}$ Grillparzer die Melancholie in ihrer Bedeutung doch eher zurückgedrängt, und zwar jeweils dadurch, daß er für ihr Erscheinen ebenso wie für ihre Überwindung plausible Gründe beizubringen suchte. Das gilt nicht nur für die Überwindung von Iphigenies und Orests Melancholie durch Mut zu Wahrhaftigkeit und Gottvertrauen, sondern genauso für den selbstmordgefährdeten Faust des Ersten Teils, der durch den neuen Tag, den Ton der Osterglocken, die erinnerte Kindheit und den Wechsel vom Winter zum Frühling ins Leben zurückgerufen wird. Ja, es gilt selbst noch für den von Sorge, Not und Blindheit geplagten Faust des Zweiten Teils, in dem sein zuletzt unbewußt auf den Tod zustürzendes Streben mit dem Altersstarrsinn des Steinalten motiviert wird. Mit dem Verfahren, für alles und jedes den einleuchtenden, natürlichen Begründungszusammenhang zu konstruieren,

Blick nimmt, wird man das Unzulängliche der von Thompson (wie Anm. 6), S. 75 gemachten Beobachtung erkennen, die besagt, daß in Weh dem, der lügt! Leons Methoden trotz ihrer moralischen Fragwürdigkeit ("in spite of being ethically questionable") zum Erfolg führen dürfen. Leons Erfolg ist eingeschränkt durch seine Flüchtigkeit und dadurch, daß er in Wahrheit nicht der Erfolg seiner Methode ist.

37 Die gleiche Erweiterung um die Dimension des Psychologischen zeigt sich in Grillparzers Verhältnis zu Ovid. Fred Wagner ("Et in Vindobona Tristia." In: Grillparzer und die europäische Tradition. Londoner Symposium 1986. Hrsg. von R. Pichl, A. Stillmark, F. Wagner und W. E. Yates. Wien 1987, S. 125) hat eine Fülle von überzeugenden Gründen dafür zusammengestellt, warum Grillparzer sich in seinem lyrischen Zyklus Tristia ex Ponto mit dem nach Tomi verbannten Ovid identifiziert hat; dabei mußte Wagners Blickrichtung auf das von Ovid Vorgegebene folgerichtig dazu führen, daß er der "psychologischen Deutung", der Grillparzer selbst "in wiederholten Deutungen Vorschub geleistet" habe, vor allem objektive äußere Parallelen der beiden Dichter-Schicksale gegenüberstellte.

38 "Zart Gedicht, wie Regenbogen, / Wird nur auf dunklen Grund gezogen; / Darum behagt dem Dichtergenie / Das Element der Melancholie." (Goethe, Sprichwörtlich.) 
schien Goethe in den Augen Grillparzers gegen sein, Goethes, eigenes Ziel zu verstoßen, seiner "eigentlichen Göttin, der Wahrheit" (III, 768) zu dienen. Grillparzer hielt sich also mit seiner Kritik prinzipiell durchaus an Goethes "leitenden Grundsatz"39 der Wahrheit aus der Iphigenie, verlieh ihr aber eine eigene, skeptischere Bedeutung. Hatte Goethe in seinem Schauspiel, wie Peter Pütz konstatiert, "gegen die im 18. Jahrhundert immer noch herrschende Lehre vom absolutistischen Primat der göttlichen Gnade" das "Prinzip menschlicher Selbstbestimmung"40 gesetzt, so zeigt Weh dem, der lügt! mehr noch als Goethes Schauspiel die Grenzen dieses Prinzips, ohne deshalb emeut zu jener früheren Lehre zurückzukehren.

Und die positive Bilanz? In Grillparzers Lustspiel widerlegt die subjektive Erfahrung des Wunders die Notwendigkeit seiner objektiven Realisierung. ${ }^{41}$ Selbsttäuschung ist da so wenig die zureichende Bedingung des Glücks wie sein Inhalt. Weder Leon noch der Bischof sind am Ende je auf Dauer aus der wirklichen in eine ästhetische Scheinwelt geflohen, sondern sie versuchen beide, die wirkliche Welt zu bewältigen, so gut sie es verstehen. Ihre Selbsttäuschung wird deshalb vom Lustspiel zwar als komisch dargestellt, aber nirgends verächtlich gemacht. Doch das Glück, ein positives Verhältnis zur Zeit zu gewinnen, und zwar zum erfüllten Augenblick der Gegenwart ebenso wie zu Vergangenheit und Zukunft, erscheint dabei allem Planen und Wollen in einem elementaren Sinn entzogen und insofern, wenn es denn doch, flüchtig nur, zustande kommt, wie ein Wunder; ein Wunder, angesichts dessen selbst die gutwilligsten religiösen Erklärungsversuche

39 Grillparzer mißbilligte an den zeitgenössischen Dichtern, daß sie in ihrer Furcht vor Epigonentum allzu oft die "leitenden Grundsätze" der großen Vorbilder Goethe, Schiller und Lessing aus den Augen verlören. (Vgl. IV, 135)

40 Peter Pütz, "Nähe und Ferne zur Antike: Iphigenie und Maria Stuart." In: Unser Commercium. Goethes und Schillers Literaturpolitik. Hrsg. von W. Barner, E. Lämmert und N. Oellers. Stuttgart 1984, S. 295.

41 In seiner bereits angesprochenen Polemik gegen die "neuern Bildungsdichter, selbst Schiller und Goethe mitgerechnet," formulierte Grillparzer (IV, 163) sein eigenes Programm: "nicht, was durch die Erweisbarkeit Billigung; was durch seine bloße Existenz Glauben erzwingt, das schien mir die wahre Aufgabe der dramatischen Poesie zu sein." Auf Grillparzers Gegenüberstellung von "Erweisbarkeit" und "Glauben" beruft sich auch Delphendahl (wie Anm. 17), S. 94, doch zeigt ihre Deutung des Lustspiel-Schlusses eine Verabsolutierung der Position des Bischofs in dessen Schlußansprache: "Der Schluss in Weh dem, der lügt! zeigt das Eingreifen einer höheren Instanz in Form von Wunder. Das Ende zeigt, dass eine Erlösung möglich ist. Allerdings erfolgt sie nicht durch eigene Kraft des Menschen, sondern in der Anerkennung einer überirdischen Macht. Die Botschaft, die verkündet wird, lautet: Der Mensch muss über das Irdische hinwegsehen und vertrauensvoll in die Zukunft blicken, die in Gott endlich wird. Es bedeutet, dass der Grillparzersche Mensch kein Vertrauen auf seine eigene Zukunft hat." (S. 84). 
ins rührend Komische umschlagen. Nur in Verbindung mit einem Wunderbegriff, der auf jeden weiteren Versuch von Erklärungen und Beschreibungen verzichtet, vermeidet Grillparzers Notiz, "[d]aß etwa Gott selbst die gesagte Lüge zur Wahrheit machte," 42 die Gefahr unfreiwilliger Komik. Dagegen sind innerhalb des Lustspiels alle Versuche der Explizierung oder beschreibenden Festlegung des Wunderbegriffs vom Autor bewußt zur Vorführung unfreiwilliger Komik genutzt. In diesem Zusammenhang ist aus Nietzsches Grillparzer-Würdigung in der Abhandlung Vom Nutzen und Nachteil der Historie fürs Leben zu lernen. Nietzsche würdigt da insbesondere die zukunftsweisende Bedeutung der Grillparzerschen These von der Unmöglichkeit, "eine durchgreifende, alle [Naturereignisse] umfassende Notwendigkeit des Geschehenden nachzuweisen." 43 Goethe hätte einen solchen Nachweis nicht für unmöglich, sondern das Nachzuweisende für von vornherein evident gehalten. Nietzsches Hinweis erklärt, warum Grillparzer dem Phänomen der Melancholie nicht mit der Souveränität Goethescher Selbstironie begegnen konnte, und er erklärt eben damit, warum es nicht Goethe, sondern Grillparzer war, dem wir eines der wenigen wirklich großen deutschen Lustspiele verdanken.

42 Vgl. oben Anm. 20.

43 Friedrich Nietzsche, Werke. Hrsg. von Karl Schlechta. 1. Bd. München 1966, S. $247 f$. 